IZA DP No. 6121

Socioeconomic Heterogeneity in the Effect of Health Shocks on Earnings: Evidence from Population-Wide Data on Swedish Workers

Petter Lundborg

Martin Nilsson

Johan Vikström

November 2011 


\title{
Socioeconomic Heterogeneity in the Effect of Health Shocks on Earnings: Evidence from Population-Wide Data on Swedish Workers
}

\author{
Petter Lundborg \\ Lund University, VU University Amsterdam, \\ HEP, CED, Tinbergen Institute and IZA \\ Martin Nilsson \\ Uppsala University, IFAU-Uppsala and UCLS
}

Johan Vikström

IFAU-Uppsala and UCLS

Discussion Paper No. 6121

November 2011

\author{
IZA \\ P.O. Box 7240 \\ 53072 Bonn \\ Germany \\ Phone: +49-228-3894-0 \\ Fax: +49-228-3894-180 \\ E-mail: iza@iza.org
}

\begin{abstract}
Any opinions expressed here are those of the author(s) and not those of IZA. Research published in this series may include views on policy, but the institute itself takes no institutional policy positions.

The Institute for the Study of Labor (IZA) in Bonn is a local and virtual international research center and a place of communication between science, politics and business. IZA is an independent nonprofit organization supported by Deutsche Post Foundation. The center is associated with the University of Bonn and offers a stimulating research environment through its international network, workshops and conferences, data service, project support, research visits and doctoral program. IZA engages in (i) original and internationally competitive research in all fields of labor economics, (ii) development of policy concepts, and (iii) dissemination of research results and concepts to the interested public.
\end{abstract}

IZA Discussion Papers often represent preliminary work and are circulated to encourage discussion. Citation of such a paper should account for its provisional character. A revised version may be available directly from the author. 


\section{ABSTRACT \\ Socioeconomic Heterogeneity in the Effect of Health Shocks on Earnings: Evidence from Population-Wide Data on Swedish Workers ${ }^{*}$}

In this paper, we estimate socioeconomic heterogeneity in the effect of unexpected health shocks on labor market outcomes, using register-based data on the entire population of Swedish workers. We effectively exploit a Difference-in-Difference-in-Differences design, in which we compare the change in labor earnings across treated and control groups with high and low education levels. If the anticipation effects are similar for individuals with high and low education, any difference in the estimates across socioeconomic groups could plausibly be given a causal interpretation. Our results suggest a large amount of heterogeneity in the effects, in which individuals with a low education level suffer relatively more from a given health shock. These results hold across a wide range of different types of health shocks and become more pronounced with age. Our results suggest that socioeconomic heterogeneity in the effect of health shocks offers one explanation for how the socioeconomic gradient in health arises.

JEL Classification: I10, I12, I14

Keywords: health, health shocks, socioeconomic status, life-cycle

Corresponding author:

Petter Lundborg

Lund University

Department of Economics

P.O. Box 7082

22007 Lund

Sweden

E-mail: petter.lundborg@nek.lu.se

\footnotetext{
* We would like to thank Caroline Hall, Matthew Lindquist, Per Johansson, and seminar participants at Lund University, Uppsala University and the EALE 2011 conference for helpful comments. The financial support of the Swedish Council of Working Life and Social Research FAS (dnr 2004-2005 and dnr 2009-0826) is acknowledged.
} 


\section{Introduction}

The socioeconomic gradient in health is one of the most widely replicated results in the social sciences. It dates back at least to the nineteenth century, when researchers documented marked health differences across different groups in society, such as royalty, the landed-gentry, and the working class (see Antonovsky (1967) for a review of the early literature on the socioeconomic gradient in health). In modern societies, the gradient is usually found to widen during working life but then narrows as people reach older ages (see e.g. van Kippersluis et al. 2009, Case \& Deaton 2005b). As shown in figure 1, this pattern also holds in countries with universal health insurance coverage and high-quality medical care, such as Sweden. ${ }^{1}$ The figure shows the fraction of members of the population in the upper- and lower-income quartiles at different ages stating that they are in bad health.

While there is general agreement about the existence of a socioeconomic gradient in health, there is little agreement about its underlying causes. In the epidemiological literature, it has traditionally been assumed that people's socioeconomic status in terms of income and/or level of education affects their health. Economists have instead explored the hypothesis that health outcomes influence socioeconomic status (e.g. Smith 1998). This is a very different explanation from the traditional one, since it suggests that health outcomes are the mechanism through which the socioeconomic gradient partly arises. Surveys by Smith (1999) and Case \& Deaton (2005a) even conclude that a larger part of the association between health and socioeconomic status in middle age and old age is likely to reflect an impact of health on socioeconomic status.

The recent economics literature has for the most part implicitly assumed that the impact of a health event on labor market outcomes is similar across different socioeconomic groups of the population. ${ }^{2}$ This is a rather restrictive assumption for a number of reasons. First, a large literature has shown socioeconomic heterogeneity in the recovery from and survival of medical conditions, such as cancers and heart diseases (e.g. Schrijvers \& Mackenbach 1994, Smith et al. 1998, Peltonen et al. 2000). In line with this,

\footnotetext{
${ }^{1}$ The survey data come from the Swedish database ULF (Survey of Living Standards). It is conducted on a yearly basis and covers a random sample of about 3000 individuals.

${ }^{2}$ One exception is Smith (1999), who estimates heterogeneity by income in the effect of a new illness on wealth and medical expenses. Smith (1999) finds that households whose pre-illness household income places them above the median income face similar medical expenses to households with below-median income but larger wealth losses.
} 
results have shown that highly educated individuals are better at adhering to medical treatments, such as AIDS and diabetes treatments (Goldman $\&$ Smith 2002). Second, recent literature has shown differences in access to medical technologies and treatments according to socioeconomic status (Rosvall et al. 2008). Third, people of a different socioeconomic status may face different incentives to return to the labor market after facing a health shock, due to the structure of the health insurance and social insurance systems. Fourth, the extent to which job tasks require good physical health is likely to vary according to socioeconomic status. Finally, it is likely that individuals of high socioeconomic status can change occupation more easily or adjust their work conditions in other ways in response to a health shock.

If substantial heterogeneity exists in the effect of health shocks on labor market outcomes by socioeconomic status, we believe that this could be an important part of the explanation for how the socioeconomic gradient in health arises. ${ }^{3}$ In this paper, we therefore advance the recent literature by focusing on socioeconomic heterogeneity in the relative effect of a large number of different types of health shocks on income. In addition, we allow the effects to vary by age. This is suggested by the cumulative advantage hypothesis, in which certain mediators of the relationship between socioeconomic status and health (e.g. smoking or social capital) accumulate over the life cycle (see e.g. Ross \& Wu 1996, Lynch 2003, Willson et al. 2007). One would then expect older individuals from lower socioeconomic groups to be especially sensitive to health shocks, which may then partly explain why the socioeconomic gradient in health increases in middle age.

For the purpose of our study, we use longitudinal, register-based data on earnings and hospitalizations for the entire population of Swedish workers. Our data and analytical approach give us a number of advantages. First, our large sample allows us to estimate heterogeneous effects by both socioeconomic status and age with great precision. In addition, the large sample size also allows us to estimate the relative importance of various types of health shocks in a given population, whereas most previous studies focus on the impact of one particular health event at a time (see e.g. Dano (2005) on the effects of accidents in Denmark).

Second, most previous studies on the impact of health shocks on labour market outcomes treat health events as exogenously given and only a small

\footnotetext{
${ }^{3}$ Note also that if the impact of a given health shock is stronger for people of low socioeconomic status, they would face a double penalty as they already face an increased risk of experiencing negative health shocks.
} 
number of recent studies address endogeneity issues(see e.g. Riphahn 1999, Au et al. 2005, Disney et al. 2006, Gómez \& Nicolás 2006). The panel structure of our data allows us to employ panel-data fixed-effects techniques and thereby account for time-invariant factors at the individual level that may be associated with both underlying health and labor market outcomes, such as chronic conditions, genes, and early life environment. Our data also allow us to distinguish between acute and planned hospitalizations. We are thus able to study the impact of health shocks that were unexpected from the individual's point of view. Moreover, by comparing the responses across educational groups we are able to difference away any remaining anticipation effects. This holds if the anticipation effects are similar for individuals with high and low education, which seems plausible from an inspection of the raw data. We are thus effectively exploiting a Difference-in-Differencesin-Differences design, whereby we compare the change in labor earnings across the treated and control groups with high and low education. We believe that this design facilitates a causal interpretation of our estimates. In addition, we perform an extensive set of placebo estimates as well as a sensitivity analysis using Difference-in-Differences matching techniques (see e.g. Heckman et al. 1997).

Third, our estimates are based on detailed register data on health shocks taken from the national inpatient hospital registers, while most previous literature uses data on self-reported health shocks. Using register data is an advantage, since there is substantial evidence of reporting bias by socioeconomic status, in that people with higher education and income report worse health for a given condition (Etilé \& Milcent 2006, d'Uva et al. 2008). ${ }^{4}$

Fourth, our data allow us to investigate some possible mechanisms that may give rise to heterogeneity in the impact of health shocks. We are able

\footnotetext{
${ }^{4} \mathrm{~A}$ potential disadvantage of using register data is that differences may exist in healthcare-seeking behavior across socioeconomic groups. It should be noted that the nominal fees for health care are very low in Sweden, however, and one should not expect any differences for that reason, although differences may still exist in health-care-seeking behavior due to differences in health knowledge across socioeconomic groups. If health knowledge is lower in the low socioeconomic group, it means that the group of loweducated individuals seeking care consists of a sample of disproportionally knowledgeable workers. This would suggest that the effect among the low-educated group is underestimated, if the low-educated workers seeking care are also better at taking care of their health than low-educated workers who should have sought care, but did not. Note also that the control group would then consist of a number of individuals who did not seek care when needed, thus further biasing the estimated difference between the treated and the controls downward.
} 
to test the extent to which the heterogeneity arises from differential access to health care and treatments, differences in the severity of health shocks, differences in occupations, and differences in the incentives to return to work after a health shock across socioeconomic groups. Knowledge about the mechanisms is of obvious policy interest. For instance, if differential access to medical care is the main reason for the observed gradient, then improved access to health care for low socioeconomic groups would be one policy option that could be used in order to weaken the gradient.

Fifth, we are able to follow individuals for up to 14 years. This allows us to consider both the short- and the long-term impact of health shocks. Since heterogeneity may exist in the long-term impact of health shocks by socioeconomic status, examining the long-term impact is important.

We start our paper by documenting large, significant, and long-run average effects of health shocks on yearly earnings. We then show that these average estimates mask substantial heterogeneity in the relative impact of health shocks across socioeconomic groups. In the short run, the effect of a health shock is much greater for individuals from lower socioeconomic groups. The difference is most pronounced for older individuals (aged 5059 ), for whom the effect of low socioeconomic status is more than twice that for individuals of high socioeconomic status.

Our results also suggest some interesting time patterns. For young individuals (aged 30-39) the difference between individuals with low and individuals with high socioeconomic status decreases with time. At older ages the picture changes completely. For both those aged 40-49 and those aged 50-59, the difference in the effect of socioeconomic status instead increases with the time since the health shock. This suggests that at old ages, there are very large differences in the long-run possibilities to cope with a negative health shock. Interestingly, we find similar heterogeneous effects of socioeconomic status and age across all types of health shocks. These results are consistent with the idea that the socioeconomic gradient in health is partly caused by the impact of health shocks on socioeconomic status. They also offer one explanation for why the socioeconomic gradient in health widens during middle age.

Besides contributing to the knowledge about the causes of the socioeconomic gradient in health, we believe that improved knowledge about heterogeneity in the impact of health shocks on labor market outcomes has important policy implications. Such knowledge may point to the possibility 
of targeted efforts towards groups who suffer disproportionally from health shocks. Moreover, the results may provide valuable information for evaluations of the cost-effectiveness of various medical interventions designed to prevent or cure disease.

The paper is organized as follows. Section 2, describes our unique population data and provides descriptive statistics. In section 3 we provide initial graphical evidence on the effects of health shocks. Section 4 presents our empirical strategy. Section 5 presents our main results, and section 6 presents an extended set of robustness analysis. Section 7 tries to explain the heterogeneous results. Finally, section 8 concludes.

\section{Data}

Our data are created by merging three Swedish population register data sets. The first register, LOUISE, covers the entire Swedish population aged 16-64 and includes variables such as age, sex, immigration status, marital status, and yearly labor earnings for the years 1990-2000. ${ }^{5}$ The second register, the Swedish National Patient Register (NPR), includes information on all inpatient care in Sweden from 1987 onwards. It includes information such as the date of admission, whether the admission was acute or planned, the length of stay, as well as rich medical data including main and secondary diagnoses (through the International Classification of Diseases, ICD) and detailed information on medical procedures. The third register is the National Causes of Death register, which records all deaths of individuals who have permanent residence in Sweden.

We create our treatment group by selecting all the admissions from the NPR for the period 1992-2000. This allows us to use information on earnings and health shocks both before and after a health shock that occurred in a specific year. We further restrict our sample to individuals who are aged 30-59 when they suffered a health shock. The reason is that a high fraction of those younger than 30 have not yet entered the labor market and many of those older than 59 are about to retire from the labor market, which prohibits an analysis of the long-term labor market

\footnotetext{
${ }^{5}$ Labor earnings record all gross cash compensation paid by employers. Beside salary, this includes for instance compensation paid by the employers during the first 14 days of a sickness spell and subsistence allowance. Sickness insurance benefits paid from the fifteenth sick day onwards, unemployment insurance benefits, disability insurance benefits, and other forms of social benefits are not included in this measure.
} 
outcomes. We also restrict the analysis to acute admissions, since we wish to focus on health shocks that are unexpected from the individual's point of view. ${ }^{67}$ For individuals with more than one acute admission during our observation period, only the first one is used in the analysis. We use the international standard and classify all the admissions into 19 major types of diseases. Of these we choose to focus on the ten most common (in terms of incidence). ${ }^{8}$

Since our focus in this paper is on the effect of health shocks on labor market outcomes, we exclude individuals who are never part of the labor force. In our main specification, we therefore only include individuals who participated in the labor force two years prior to the potential shock year. ${ }^{9}$ We define labor force participation as having a yearly labor income larger than one Price Base Amount (between 33,000 SEK (€3,300) and 38,000 SEK (€3,800) depending on the year). ${ }^{10}$

The control group consists of all the individuals who are part of the labor force and who potentially could have suffered a negative health shock in each given year but who did not. The number of time periods is restricted by our observation period of 1990 to 2004. Note that this sampling implies that an individual who did not suffer a health shock may be included in the control group for more than one year. In order to keep the empirical analysis manageable from a computational point of view, we randomly sample 3 percent of the individuals in the control group in each given

\footnotetext{
${ }^{6}$ An acute admission is more likely to be unexpected than a planned admission. One cannot rule out anticipation of acute health shocks, however, and we discuss this in more detail in the methods section.

${ }^{7}$ We also exclude admissions related to pregnancies.

${ }^{8}$ We exclude symptoms, signs, and abnormal clinical and laboratory findings, not classified elsewhere (ICD-9: 780-799, ICD-10: R00-R99). This leaves us with infectious diseases (ICD-9: 0010-139, ICD-10: A00-B99), cancer (ICD-9: 140-239, ICD-10: C00D48), mental and behavioral problems (ICD-9: 290-319, ICD-10: F00-F99), diseases of the nervous system (ICD-9: 320-359, ICD-10: G00-G99), respiratory diseases (ICD9: 460-519, ICD-10: J00-J99), heart diseases (ICD-9: 390-459, ICD-10: I00-I99), diseases of the digestive organs (ICD-9: 520-579, ICD-10: K00-K93), diseases of the musculoskeletal system and connective tissues (ICD-9: 710-739, ICD-10: M00-M99), diseases of the genito-urinary system (ICD9: 580-629, ICD-10: N00-N99), and external accidents (ICD-9: 800-1000, ICD-10: S00-T98).

${ }^{9}$ We perform a robustness analysis with respect to this restriction, and our results are insensitive to restricting the sample to those participating in the labor force three years before the shock year.

${ }^{10}$ The price base amount is a measure set by the Swedish Government a year at a time. The amount is calculated based on changes in the consumer price index. The price base amount has various uses, including ensuring that sickness benefits, study support, etc., do not decline in value because of an increase in the general price level.
} 
year. $^{11}$

\subsection{Descriptive statistics}

Table 1 provides descriptive statistics on the fraction of the working population affected by a health shock by age and level of education (we present statistics for 1995). The table reveals a pronounced age pattern, where health shocks unsurprisingly become more common as people reach old age. About 3.5 percent experience a health shock in the youngest age group (30-39), whereas the corresponding figure in the oldest age group (50-59) is 5.5 percent.

There are large differences in the prevalence of health shocks by level of education, however. In the table, we divide the population into two groups: individuals with a university education (high education) and individuals without a university education (low education). The latter group is much more likely to be affected by negative health shocks compared with individuals with a university education. This pattern holds for all the age groups and for almost all the types of health shocks. For instance, in the youngest age group, the likelihood of experiencing at least one health shock in a given year is about 40 percent larger among the low-educated group than among the group with high education. A notable exception is cancer, for which the incidence is the same regardless of educational background.

Table 2 reports sample statistics for a number of background characteristics, measured one year before the potential health shock. The statistics show that males, immigrants, and individuals with a child in the household or who are single are all more likely to experience a health shock. These patterns hold for all the age categories. As expected, the labor earnings are greater for those who do not experience a health shock.

\section{Graphical analysis}

In this section we illustrate some of the most interesting patterns in the data graphically. This serves as a background for our empirical specification. Figure 2 shows, for high-educated and low-educated individuals,

\footnotetext{
${ }^{11}$ Since we follow the treated and non-treated over a long time period, some of the individuals in the control group will suffer a health shock within our observation window. In order to handle this we follow the dynamic treatment assignment methods developed in Fredriksson \& Johansson (2008) and include the controls up until the time they suffer their first health shock.
} 
the average labor earnings for the treatment and the control group, respectively. Earnings are displayed by time from the potential shock year (time $=0$ ), i.e. the year in which the treated individuals experience a health shock and the year in which the individuals in the control group potentially could have experienced a shock.

The figure shows that both the level and the pre-shock trends in earnings differ between the treated and the controls in both the high-educated and the low-educated group. Clearly, several years before the actual shock, labor earnings already increase faster in the control group. There also already seems to be a small decline in labor earnings among the treated one year before the actual health shock. This suggests that there are some health shocks that are anticipated and/or affect the individual's labor earnings before they actually force the individual to seek medical help. This also means that accounting for pre-shock trends and anticipation effects will be important for our empirical strategy. However, even taking pre-treatment trends into account, it is still apparent that there is a large decrease, for both the high-educated and the low-educated group, in the labor earnings in the year of the negative health shock.

We next graphically display the possible heterogeneous effects. Figure 3 -figure 5 show, for each age group, the ratio between the average labor earnings for individuals with high education and those for individuals with low education in the treatment and control group, respectively. Since the average income is higher among individuals with high education all the ratios are above one. ${ }^{12}$ For the treated, the earnings ratio jumps up in the shock year in all the age groups. For the control groups we see no such jumps. This means that a health shock decreases income relatively more for individuals with low education compared with individuals with high education. This captures socioeconomic heterogeneity in the shortterm effect of health shocks. Besides this immediate difference, the figures also provide a first indication of substantial heterogeneity in the long-run effects. Several years after the health shock the earnings ratio between treated individuals with high education and those with low education is still much higher compared with the same ratio in the control group.

Figure 3-figure 5 also have important implications for our empirical strategy. In figure 2, illustrating average labor earnings, we see important

\footnotetext{
${ }^{12}$ One exception is 10 years before the shock year for individuals aged $30-39$. This reflects the fact that some individuals with longer university education have not yet completed their education at this time point.
} 
differences in pre-shock trends and anticipation effects. Figure 3-figure 5, where the focus is on the earnings ratios between mean labor incomes for high-educated individuals and those for low-educated individuals, there are no important differences in pre-shock trends. Before the year of the health shock, the earnings ratio is very similar between the treatment and the control group. Moreover, there is no decline in the earnings ratio among the treated one year before the actual shock. In other words, the pre-shock trends and anticipation effects are remarkably similar for individuals with high and low education, so that focusing on heterogeneous effects clearly mitigates one of the main issues with estimating the effects of health shocks. As a further illustration, figure 8 in the appendix shows similar figures for each type of health shock. These figures show that the earnings ratios are fairly stable before the shock year for almost all types of health shocks, even for cancer and mental and behavioral diseases. This further supports the focus on heterogeneous effects.

\section{Empirical strategy}

The aim of this paper is to estimate the short- and long-run heterogeneous effects of a negative health shock on labor earnings. To this end, we focus on acute admissions, since there are good reasons to assume that they are more or less unanticipated from the individual's perspective. However, even if acute admissions are unanticipated, the probability of experiencing an acute admission may be correlated with observed and unobserved individual characteristics like labor preferences, early life environment, and/or underlying ability. We therefore include an extended set of fixed effects as well as controls for differences in pre-shock trends in all our empirical models.

Our baseline heterogeneous effects model, for labor earnings for individual $i$ in time period $t$ in calendar year $z$, is:

$$
\begin{aligned}
y_{i z t}= & \lambda_{t}+\lambda_{z}+\lambda_{i}+\sum_{\tau=0}^{T} \delta_{\tau} I(t=\tau) D_{i}+I^{L E}\left[\sum_{\tau=0}^{T} \delta_{\tau}^{L E} I(t=\tau)\right] D_{i}+ \\
& \gamma_{1} D_{i} t+\gamma_{2}\left(1-D_{i}\right) t+I^{L E}\left[\gamma_{1}^{L E} D_{i} t+\gamma_{2}^{L E}\left(1-D_{i}\right) t\right]+\varepsilon_{i z t} .
\end{aligned}
$$

We normalize time so that year 0 is the shock year. $D_{i}$ is an indicator 
variable taking the value 1 if the individual suffers a health shock in year 0 and 0 otherwise, and $I^{L E}$ is an indicator variable taking the value 1 if the individual has low education. The coefficients of interest are $\delta_{0}, \ldots, \delta_{T}$, which capture the main effect of a health shock in the shock year, one year after the shock, and so on, and in particular $\delta_{0}^{L E}, \ldots, \delta_{T}^{L E}$, which capture the additional effect for individuals with low education. In the analysis we take age into account by running separate regressions for three different age groups.

This model controls for an extended set of fixed effects, including the timing with respect to the shock year (or potential shock year for the controls), $\lambda_{t}$, calendar time fixed effects, $\lambda_{z}$, as well as individual fixed effects, $\lambda_{i} \cdot{ }^{13}$ These fixed effects control for changes over time, aggregated changes in the economy, and all time-invariant factors at the individual level, respectively. We also control for underlying pre-shock trends in labor earnings by including linear trends that are allowed to vary by both treatment status and level of education. ${ }^{14}$

After controlling for fixed effects and general pre-shock trends, some pre-treatment effects may still remain since some health shocks could still be more or less anticipated and/or already show an effect before the actual admission. Here, it helps to focus on heterogeneous effects, which compare the responses to a health shock across educational groups. Our model could be viewed as a Difference-in-Difference-in-Differences model in which we compare the change in labor earnings across treated and control groups with high and low education. If the anticipation effects are similar for individuals with high and low education, our heterogeneous effects estimate could still be given a causal interpretation. Based on the figures presented in section 3 this seems highly plausible. Moreover, note that if the anticipation effects are larger for the low educated, as one may suspect, this will bias our heterogeneous effect estimates downwards. The important heterogeneous effects that we document could therefore be seen as a lower bound to the actual heterogeneous effects.

When comparing the size of the effects for individuals with high and

\footnotetext{
${ }^{13}$ In one specification we also include a set of covariates instead of individual fixed effects. All the covariates are measured one year prior to the treatment in order to handle the potential problem of the control variables being affected by the health shock. For that reason we cannot include these background characteristics and individual fixed effects at the same time.

${ }^{14}$ We also run models using quadratic and even cubic trends but the results are insensitive to including more flexible controls for trends.
} 
low education, it is important to keep in mind that the starting level differs across the groups. This means that even if the effect in absolute numbers is larger for the high educated, the relative effect on labor income may still be larger for the low educated. We therefore construct a relative income measure that sets the individual's current earnings in relation to the average earnings level among his peers (i.e. those of the same age and the same level of education). More precisely, we divide the population into six groups according to age and level of education, and construct a relative outcome measure by dividing the individual earnings rate by the average earnings within the group. ${ }^{15}$

We believe that this extended fixed-effects specification, in which we focus on unexpected health shocks and compare the size of the change in earnings across educational groups, facilitates a causal interpretation of our estimates. However, since we rely on observational data we perform an extensive set of robustness analyses. We therefore: (1) perform placebo estimates to test for any significant pre-shock responses two years before the actual shock (the placebo estimates will be performed jointly and separately for our ten types of health shocks); (2) use DID matching in the spirit of Heckman et al. (1997) instead of running fixed-effects models; (3) use detailed data on the number of medical procedures and the number of diagnoses in order to investigate whether our results are driven by differences across groups in the severity of the health shocks; (4) estimate models in which we divide the population into finer educational groups; (5) run regressions only using the individuals who survive throughout the entire observation window in order to assess whether our results are affected by the differential survival rate across levels of education and age.

\section{Results}

\subsection{Average effects}

As a baseline case, table 3 shows estimates of the average effects of a health shock. The model in column (1) includes basic controls for calendar year and time fixed effects. In model (2) we then add an extended set of observed

\footnotetext{
${ }^{15}$ We divide by the average earnings one year prior to the year in which the treated experience a health shock and the controls potentially could have experienced a health shock. The reason for this is that this earnings level should be unaffected by the health shocks.
} 
characteristics. ${ }^{16}$ Model (3) includes individual fixed effects, and model (4) adds separate linear trends for the treated and non-treated. In all four specifications, we find large and significant effects of a health shock on labor earnings during the year of the health shock. Remember that we use a relative income measure, so that the coefficients should be interpreted in terms of relative effects. For instance, the estimate of the average effect in model 4 , shown in table 3 , suggests that income on average decreases by 9 percent directly after the health shock.

Interestingly, the long-term effects are larger than the short-term effects. From model 4 in table 3 , we see that the effect is 13 percent five years after the shock, compared with 9 percent in the shock year. It clearly indicates that health shocks have sizeable, long-lasting, and economically significant effects on labor outcomes.

\subsection{Heterogeneous effects by level of education and age}

We now turn to the main purpose of our paper, which is to investigate heterogeneous responses to health shocks by level of education and age. Note that in all the models in this subsection, we control for individual fixed effects as well as flexible linear trends by treatment status and level of education. We run separate regressions for the age groups 30-39, 40-49, and 50-59, and measure the difference in the effects between low-educated individuals (no university education) and high-educated individuals (some university education) using an interaction effect. The results from this exercise are shown in table 4.

The results reveal important heterogeneous effects. In the year of the health shock, labor earnings decline by between 5 percent and 6 percent for the high educated in all three age groups. The effect for the low educated is almost twice as large in all the age groups (between 9 percent and 12 percent). This means that individuals from lower socioeconomic groups not only suffer from more frequent health shocks but also suffer disproportionally from a given health shock.

Beside these clear, short-term differences in effects across groups, there are also some interesting time patterns. For the youngest group, the difference between the high educated and the low educated decreases with time

\footnotetext{
${ }^{16}$ We include gender, level and type of education, immigrant status, age, residence municipality, marital status, and sector of employment.
} 
after the shock. During the shock year, the effect on earnings is almost 80 percent larger among the low educated. After two years, this difference has decreased to 40 percent, and five years after the shock, the effect is basically the same for high-educated and low-educated individuals. For individuals in middle and old age, the time pattern is completely different. At these ages, the difference in the effect for high-educated and low-educated people increases with the time since the shock. Five years after the shock, the effect is almost three times as large among the low educated in the 40-49 group and almost seven times as large in the 50-59 age group.

\subsection{Heterogeneous effects by type of health shock}

To what extent do the heterogeneous effects differ by type of health shock? Table 5 presents separate estimates for our ten major types of health shocks. As in the previous section, we show separate estimates by level of education and age. The first, second, and third panels present the effect on yearly earnings in the shock year, two years after the shock, and five years after the shock, respectively. In order to make the presentation of the results more transparent, we do not report standard errors and only indicate significance using stars.

As expected, the main effects differ to quite a large extent across the types of health shocks. The difference in the effects between the low educated and the high educated are, however, very similar across all the types of health shocks. In order to illustrate this pattern, Figure 6 and Figure 7 display how the heterogeneous effect for the low educated vary by time, age and type of health shock. These figures show that in the short run, the low educated experience more severe effects on labor earnings in all the age categories and for all the types of health shocks. In the long run, however, the difference between the high educated and the low educated in the youngest age group disappears for almost all the types of health shocks. For the two older age groups we see the opposite pattern, with an increasing difference between the high educated and the low educated over time for most types of health shocks. This means that the pattern we documented in the previous subsection shows up for almost all types of health shocks. 


\section{Robustness analysis}

\subsection{Placebo effects}

We next proceed by checking the robustness of our main results. We start by providing some placebo estimates, in which we move the time of the shock two years back in time, which is before the actual acute admission took place. If we find significant placebo effects, this serves as an indication that our previously estimated effects do not represent an effect of the actual health shock but rather the effect of some other time-variant group-specific characteristic influencing both the probability of suffering a negative health shock and the decline in labor earnings.

Table 6 presents the placebo estimates of both the main effect and the interaction effect, which measure the difference in the effects between the low educated and the high educated, using our most extended model specification with individual fixed effects and linear trends. These placebo estimates indicate significant pre-treatment effects for both the high educated and the low educated. However, all the pre-shock effects are very small, and the statistical significance could to a large extent be explained by the large sample size. For instance, at ages 50-59, the placebo estimate of the interaction effect is ten times smaller than the estimate of the effect in the shock year. Moreover, table 7 shows that most pre-treatment effects disappear when we also separate the estimates by type of health shock. In fact, out of 30 estimates of the interaction effect that measure the difference in the effects between low educated and high educated, we find only one that is significant at the 5 percent significance level. All these placebo estimates support our empirical strategy and confirm that it is important to have a long panel with extended information both before and after the health shocks. We therefore see no reason to change our main conclusions.

\subsection{DID matching}

In our main analysis, we use a flexible specification with an extended set of fixed effects and controls for differences in underlying trends. One alternative to this specification is to use a Difference-in-Differences (DID) matching approach (see e.g. Heckman et al. 1997). This provides a nonparametric estimate of the same parameters as in our main model. Another potential benefit is that the treatment and control groups become balanced 
in terms of covariates. In this subsection, we check the robustness of our main results when using this alternative specification. More specifically, we first perform a one-to-one propensity score matching for each shock year using all our observed covariates. ${ }^{17}$ For this matched sample we then compare the difference in labor earnings two years before the shock with the labor earnings in the shock year, one year after the shock, and so on. Table 8 presents DID-matching estimates of the short-run and long-run effects. These estimates are very similar to our main estimates, including the increase in the effect over time. If anything the effects are in general somewhat larger in the short run and somewhat smaller in the long run compared with the estimates from our main empirical strategy. All in all, we believe that the results using the DID-matching approach support our main conclusions.

\subsection{Detailed measure of education}

In the analysis so far, we focused on heterogeneity in the impact of health shocks, using only two educational categories: individuals with and without university education. Do our conclusions change if we use a more detailed measure of education? To investigate this, we next show estimates using a more detailed measure of education, for which five different educational groups are created. ${ }^{18}$ The estimates of the effects for each educational group and for each age group are presented in table 9 . For all the educational groups and for all the age groups, except for individuals aged 30-39 with a long university education, there is a large initial drop in the shock year. In the long run we see no difference between the high-school educated and the university educated in the youngest age group, whereas for individuals in middle and old ages the difference between the lowest and the highest educated widens with time since the health shock. These patterns are again the same as in our main analysis.

\footnotetext{
${ }^{17}$ Note that all the covariates are measured one year before the shock.

${ }^{18}$ The five groups are individuals with no high-school education, short high-school education (two years or fewer), long high-school education (three years), short university education (two years or less), and individuals with long university education (more than two years).
} 


\subsection{Analysis using survivals}

If the fraction that dies during our observation window differs in a systematic way across treatment groups, level of education, and age, our estimates may be biased. ${ }^{19}$ In order to assess the extent of this potential problem, we can examine the fraction of individuals who die within our observation period for the different groups. These sample statistics, shown in table 10, indicate large differences in the survival rate. Low-educated and old individuals who experience a health shock are more likely to die. We therefore re-estimate our model, now only including individuals who survive the entire observation period. The estimates from this exercise are presented in table 11. Again, we find that in the long run, the difference between the low educated and the high educated disappears for the younger group, but widens for the two older cohorts. Our conclusions thus remain unaffected.

\subsection{Severity of the health shocks}

Our results so far suggest that individuals with low education have a worse ability to cope with a health shock. An alternative explanation would be that individuals with low education experience more intense shocks than individuals with high education, even though the diagnosis may be the same. One reason for this would be if the low educated on average wait longer before going to the hospital after feeling sick, so that the condition becomes worse once in hospital. If so, we are not really measuring the same thing across groups with low and high education. In order to test for this alternative explanation, we use information on the number of diagnoses and the number of medical procedures as a proxy for the severity of the health shock. Needless to say, this does not provide a perfect measure, but it is not far-fetched to assume that a second (or third) diagnosis and the number of medical procedures (e.g. surgeries) may imply a more severe health shock. ${ }^{20}$

Table 12 displays descriptive statistics for the number of diagnoses (including the main diagnosis) and the number of medical procedures by level

\footnotetext{
${ }^{19}$ Note, however, that if low-educated people are more likely to die following a health shock, this may result in estimates that underestimate the difference in effects across low- and high-educated groups. The reason is that the fraction of "frail" individuals in the low-educated group will decrease faster over time.

${ }^{20}$ For the number of medical procedures, the interpretation is somewhat more difficult, since many medical procedures could be a sign of worse health but could also be an indicator of better treatment, which potentially could improve the long-term outcome.
} 
of education and age. We see that the vast majority of individuals only have a main diagnosis, even though the probability of a secondary diagnosis increases with age. Most importantly, there are no differences between the low educated and the high educated in terms of the number of diagnoses. Unlike the number of diagnoses, there does not seem to be a clear age pattern when it comes to the number of medical procedures. There are also only small differences between the high educated and the low educated.

We also re-estimate our main heterogeneous effects model taking the number of diagnoses and the number of medical procedures into account. More specifically, we interact our treatment variable with the number of diagnoses and the number of medical procedures. ${ }^{21}$ If including these additional interactions significantly changes our estimate of the difference in the effect of a health shock between the high educated and the low educated then differences in the severity of the health shocks explain an important part of the heterogeneous effects. The results from this exercise are presented in table 13. For comparison, we also include the baseline results from table 4 . We only report the low-education interaction effect, since the main effects in the new models now represent the effect for the baseline category. They are therefore not comparable with our baseline results.

We find that the heterogeneous effects estimate of the additional effect for the low educated is distinctly similar across all three models. This holds for all the age groups and for the short-term as well as the long-term heterogeneous effects. Even if these measures are imperfect proxies for the severity of the health shock, these sample statistics and these estimates show that it is unlikely that the observed heterogeneous effects are purely an effect of differences in the severity of the health shock.

\section{$7 \quad$ What explains the heterogeneous effects?}

What could then explain the observed heterogeneity in the effects? As discussed in the introduction, there are several possible explanations. First of all, the economic incentive to return to work after a health shock is stronger among the high educated, due to their higher earnings and due to the fact that, as in most countries, there are maximum benefit levels in the Swedish social insurance. Replacement rates in the Swedish social

\footnotetext{
${ }^{21}$ These variables are coded as dummy variables. The number of diagnoses is 1,2 , 3 , or $\geq 4$; the number of operations is $0,1,2$, or $\geq 3$. The baseline categories are 1 diagnosis and 0 operations.
} 
insurance systems are capped at a relatively low ceiling, which means that low SES people may have weaker incentives to return to work after a health shock compared with high SES people. ${ }^{22}$ Hence, high and low educated individuals may have different moral hazard profiles. It could also be the case that the highly educated are able to acquire more information and handle contact with the health-care system better, allowing them to receive more appropriate treatment. Moreover, the low educated are to a higher extent employed in physical/blue-collar occupations. We find it plausible that a decline in health complicates the return to work for these individuals compared with those within white-collar professions due to the character of the jobs.

Starting with economic incentives, we again note that in the previous section we found no significant differences by level of education in the severity of the health shocks. Given this fact, and if the differences in economic incentives are an important factor, we would expect individuals with high education to leave the hospital and return to work more quickly. For that reason we test the economic incentives explanation by including interaction effects between the length of the stay in the hospital (1-5 days, 6-10 days, 11-15 days, 16-20 days, and $\geq 21$ days). If the heterogeneous effects change when including this interaction economic incentives offer one important explanation for our heterogeneous effects estimates.

To test whether the result could be explained by differences in the quality of the treatment, we interact the treatment with an indicator for whether the treating hospital was a university hospital. In Sweden, the university hospitals usually have the most advanced medical technology. It is therefore not far-fetched to assume that university hospital status provides quite a good measure of the quality of the treatment. Finally, in order to test whether the result could be explained by the sector of occupation, we include an interaction effect between the individual's sector

\footnotetext{
${ }^{22}$ The Swedish sickness insurance provides economic compensation when a worker is too sick to carry out his or her regular job. This insurance automatically covers all of the employed workers. The benefits in the Swedish sickness insurance are income-related; the size of the benefits depend on the person's wage prior to the sick spell. The insurance consists of two main benefits, sickness benefit (SI) and disability benefit (DI). The SI is supposed to cover part of the income loss due to temporary illness. DI compensates individuals whose work capacity is permanently reduced. The replacement rates have changed over time, but the rates were capped at a relatively low ceiling throughout our observed time period (about 25 percent of the workers have an income above the ceiling).
} 
of employment the year prior to the shock and the year of the shock. ${ }^{23}$ If the heterogeneous effect diminishes or disappears with this specification, the sector of employment is an important mechanism behind the previously found results.

The results from these different estimations are presented in table 14 . The top, middle, and last panels show the effect on yearly earnings for the age groups 30-39, 40-49, and 50-59, respectively. For comparison the baseline results from table 4 are also included in the table. These new estimates are in most cases similar to the baseline estimates, including the long-run differences across age groups. Given this and the fact that the other results are in line with the baseline estimates, we find no support for different moral hazard profiles, differences in treatment quality, or differences in the sector of employment being able to explain the observed heterogeneous effects.

\section{Conclusions}

In this paper we used unique register-based data on the entire population of Swedish workers to estimate heterogeneity in the effect of health shocks on labor earnings. Our large-scale register data set covered the entire population of Swedish workers over a period of 15 years, which gives our results an unusually high degree of representativeness. Using panel fixed-effects techniques, focusing on unexpected health shocks, and comparing the outcomes over time for low- and high-educated workers, we argued that we came close to estimating the causal impact of health shocks on earnings.

Our results suggest that individuals with low education suffer disproportionally from a given health shock, although there were important differences in the long-run effects across age groups. For the youngest cohort, aged 30-39, the difference between the high educated and the low educated diminishes over time, whereas the difference increases over time for the older cohorts, 40-49 and 50-59. These results are also in line with the cumulative advantage hypothesis, which states that some mediators of the socioeconomic status and health relationship (e.g. smoking or social capital) accumulate over the life cycle (see e.g. Ross \& Wu 1996, Lynch 2003).

\footnotetext{
${ }^{23}$ We use Statistic Sweden's Svensk Näringsgrensindelning on a two-digit level as an indicator of the sector of employment.
} 
The fact that individuals from lower socioeconomic groups suffer disproportionally, especially in middle and old age, offers one explanation for why the socioeconomic gradient in health widens during middle age. Our results show that at least part of this widening is due to the fact that individuals in lower socioeconomic groups who experience a health shock lose a disproportionally large amount of income. This makes them fall further down in the income distribution, which further strengthens the socioeconomic gradient in health during middle age. Our findings also support the arguments by e.g. Case \& Deaton (2005a) and van Kippersluis et al. (2009) that in order to understand the socioeconomic gradient in health, one needs to take a life-cycle perspective.

What could then explain the heterogeneity in the impact of health shocks? We have attempted to test whether different moral hazard profiles, differences in treatment quality and/or different sectors of employment, and differential survival across groups are important explanations. Our estimates suggest that none of these explanations explain a major part of the observed heterogeneous effects. This may suggest that differences in adherence to medical treatment across socioeconomic groups are an important explanation, although we are unable to test for this in the present paper. We believe that an improved understanding of the causes behind heterogeneity in the effects is an important area for future research.

The existence of a large amount of heterogeneity in the impact of health shocks on labor outcomes is an important insight for policy-makers. As discussed in the introduction, such heterogeneity means that policy advice that is based on average estimates may be severely misguided. Our results show that there may be gains in considering heterogeneous effects, for instance when evaluating new medical technologies and treatments, where the outcome measures include economic outcomes, such as income. By considering heterogeneous effects, it may be possible to identify groups in which the treatments have a beneficial cost-benefit ratio, whereas the average effects may mask such heterogeneity in the cost-benefit ratio. Targeted interventions towards such groups may thus lead to a more efficient use of health-care resources. 


\section{References}

Antonovsky, A. (1967), 'Social class, life expectancy and overall mortality', The Milbank Memorial Fund Quarterly 45(2), 31-73.

Au, D. W. H., Crossley, T. F. \& Schellhorn, M. (2005), 'The effect of health changes and long-term health on the work activity of older canadians', Health Economics 14(10), 999-1018.

Case, A. \& Deaton, A. (2005a), 'Health and wealth among the poor: India and south africa compared', American Economic Review 95(2), 229-233.

Case, A. \& Deaton, A. S. (2005b), Broken down by work and sex: How our health declines, in 'Analyses in the Economics of Aging', NBER Chapters, National Bureau of Economic Research, Inc, pp. 185-212.

Dano, A. M. (2005), 'Road injuries and long-run effects on income and employment', Health Economics 14(9), 955-970.

Disney, R., Emmerson, C. \& Wakefield, M. (2006), 'Ill health and retirement in britain: A panel data-based analysis', Journal of Health Economics 25(4), 621-649.

d'Uva, T. B., Doorslaer, E. V., Lindeboom, M. \& O'Donnell, O. (2008), 'Does reporting heterogeneity bias the measurement of health disparities?', Health Economics 17(3), 351-375.

Etilé, F. \& Milcent, C. (2006), 'Income-related reporting heterogeneity in self-assessed health: evidence from france', Health Economics 15(9), 965981.

Fredriksson, P. \& Johansson, P. (2008), 'Dynamic treatment assignment', Journal of Business and Economic Statistics 26(4), 435-445.

Goldman, D. P. \& Smith, J. P. (2002), 'Can patient Self-Management help explain the SES health gradient?', Proceedings of the National Academy of Sciences of the United States of America 99(16).

Gómez, P. G. \& Nicolás, A. L. (2006), 'Health shocks, employment and income in the spanish labour market', Health Economics 15(9), 9971009 . 
Heckman, J. J., Ichimura, H. \& Todd, P. E. (1997), 'Matching as an econometric evaluation estimator: Evidence from evaluating a job training programme', Review of Economic Studies 64(4), 605-54.

Lynch, S. M. (2003), 'Cohort and life-course patterns in the relationship between education and health: A hierarchical approach', Demography 40(2), pp. 309-331.

Peltonen, M., Rosen, M., Lundberg, V. \& Asplund, K. (2000), 'Social patterning of myocardial infarction and stroke in sweden: Incidence and survival', American Journal of Epidemiology 151(3), 283-292.

Riphahn, R. T. (1999), 'Income and employment effects of health shocks a test case for the german welfare state', Journal of Population Economics 12(3), 363-389.

Ross, C. E. \& Wu, C.-L. (1996), 'Education, age, and the cumulative advantage in health', Journal of Health and Social Behavior 37(1), pp. $104-120$.

Rosvall, M., Chaix, B., Lynch, J., Lindstrom, M. \& Merlo, J. (2008), 'The association between socioeconomic position, use of revascularization procedures and five-year survival after recovery from acute myocardial infarction', BMC Public Health 8(1), 44.

Schrijvers, C. T. \& Mackenbach, J. P. (1994), 'Cancer patient survival by socioeconomic status in seven countries: a review for six common cancer sites [corrected]', Journal of Epidemiology and Community Health 48(5), 441-446.

Smith, G. D., Hart, C., Watt, G., Hole, D. \& Hawthorne, V. (1998), 'Individual social class, area-based deprivation, cardiovascular disease risk factors, and mortality: The renfrew and paisley study', Journal of Epidemiology and Community Health (1979-) 52(6), pp. 399-405.

Smith, J. P. (1998), 'Socioeconomic status and health', The American Economic Review 88(2), 192-196.

Smith, J. P. (1999), 'Healthy bodies and thick wallets: The dual relation between health and economic status', Journal of Economic Perspectives 13(2), 145-166. 
van Kippersluis, H., Van Ourti, T., O'Donnell, O. \& van Doorslaer, E. (2009), 'Health and income across the life cycle and generations in europe', Journal of Health Economics 28(4), 818-830.

Willson, A. E., Shuey, K. M. \& Elder, Jr., G. H. (2007), 'Cumulative advantage processes as mechanisms of inequality in life course health', American Journal of Sociology 112(6), 1886-1924. 
Figure 1: The socioeconomic gradient in health by age. Based on Swedish survey data from 1975-2007

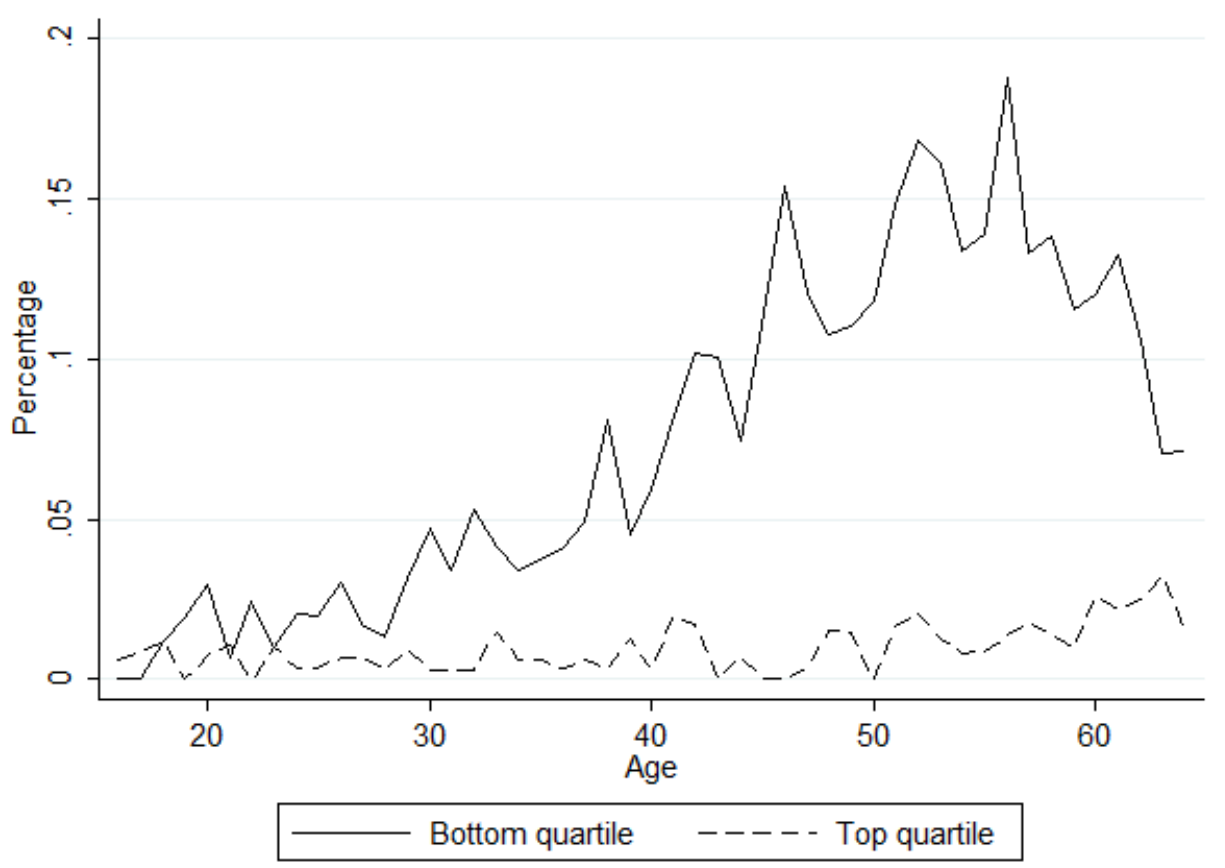

Figure 2: Yearly labor earnings before and after shock year by level of education

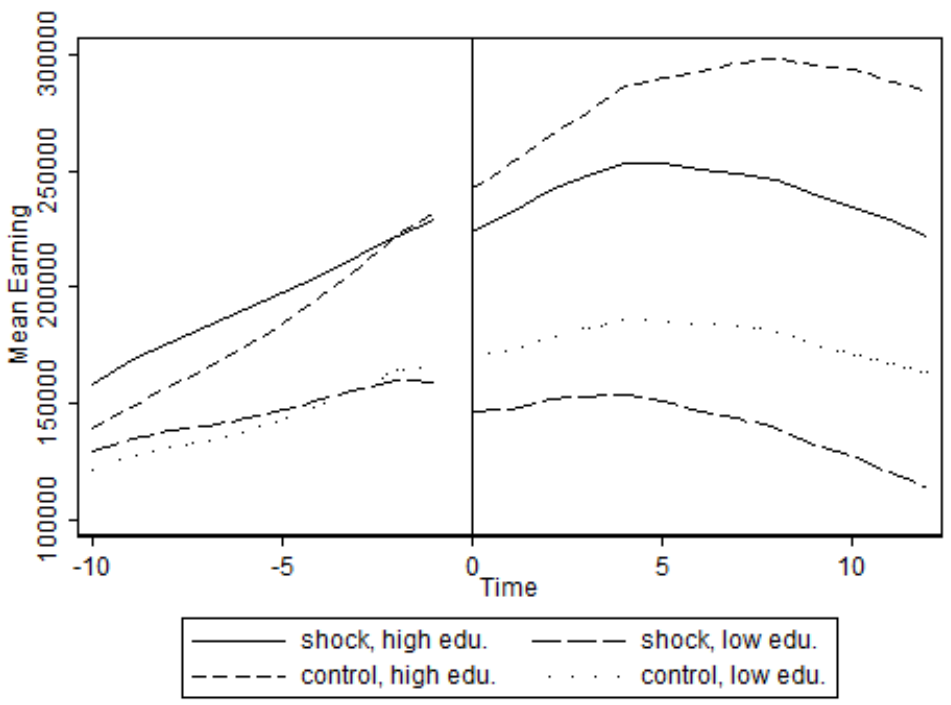


Figure 3: Ratio between mean labor earnings for high educated shock (control) and low educated shock (control). Age 30 - 39

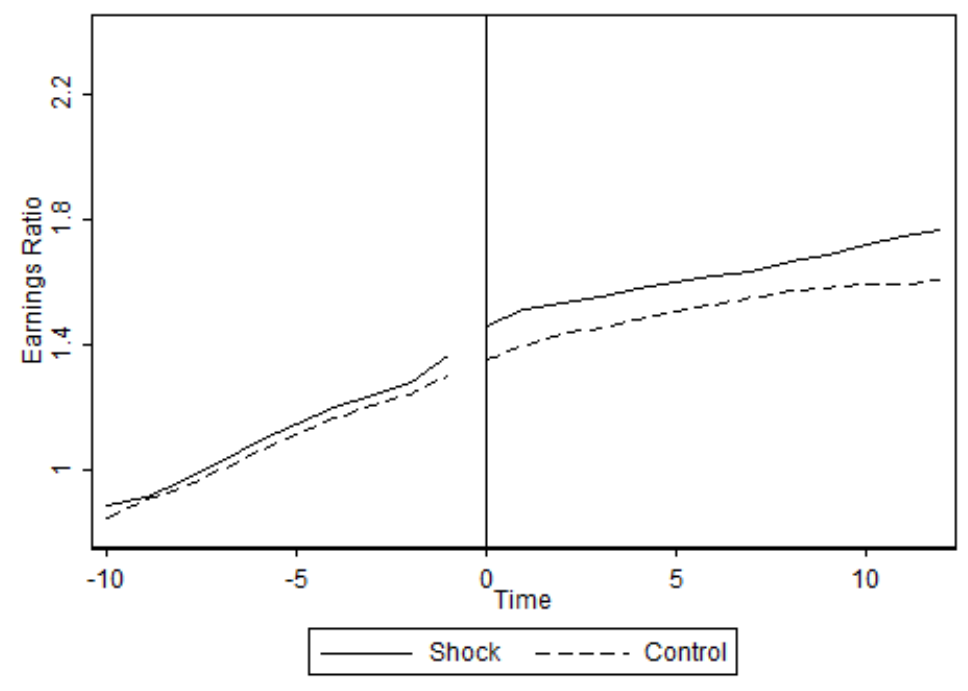

Figure 4: Ratio between mean labor earnings for high educated shock (control) and low educated shock (control). Age 40 - 49

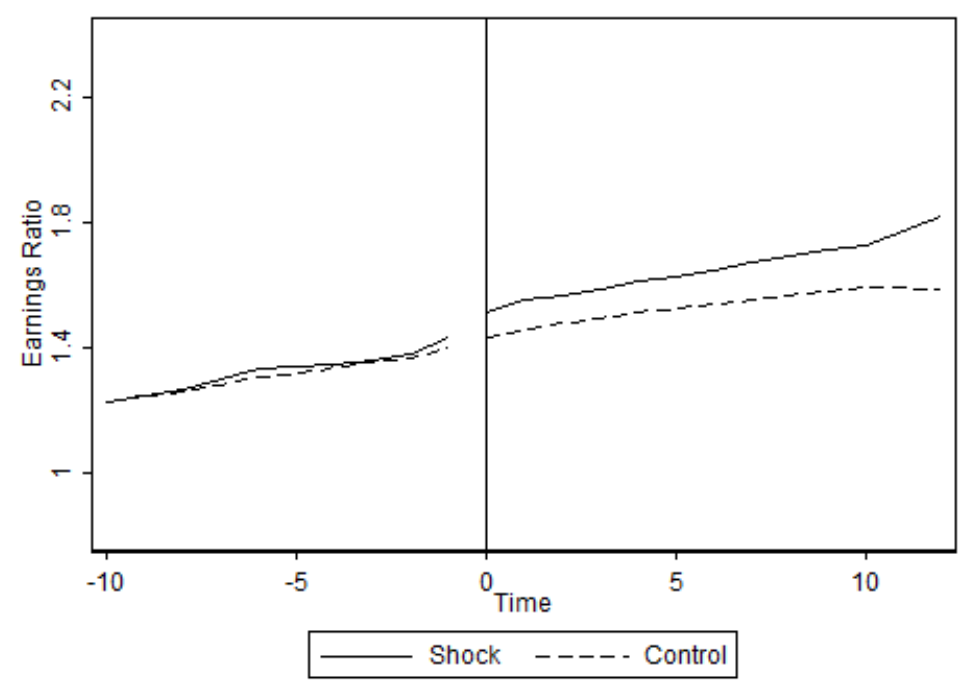


Figure 5: Ratio between mean labor earnings for high educated shock (control) and low educated shock (control). Age 50 - 59

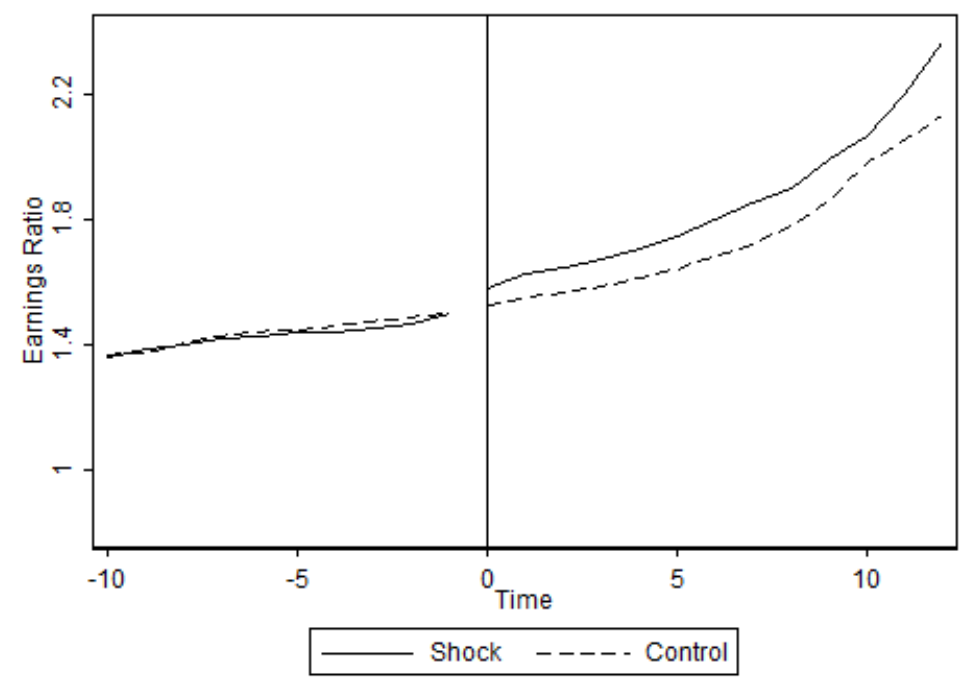

Figure 6: Difference between high educated and low educated in the effect of health shocks. By age and type of health shock

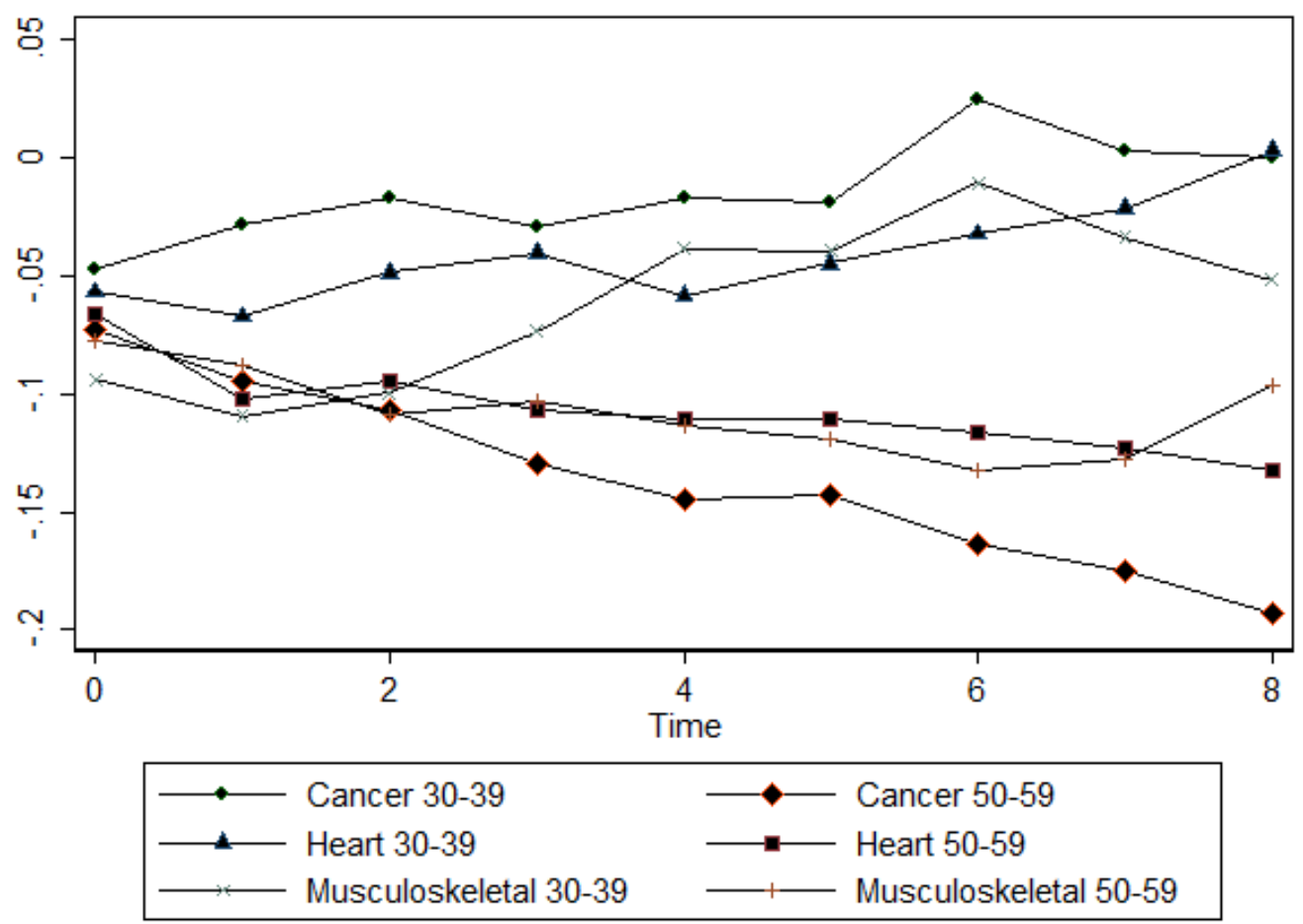


Figure 7: Difference between high educated and low educated in the effect of health shocks. By age and type of health shock

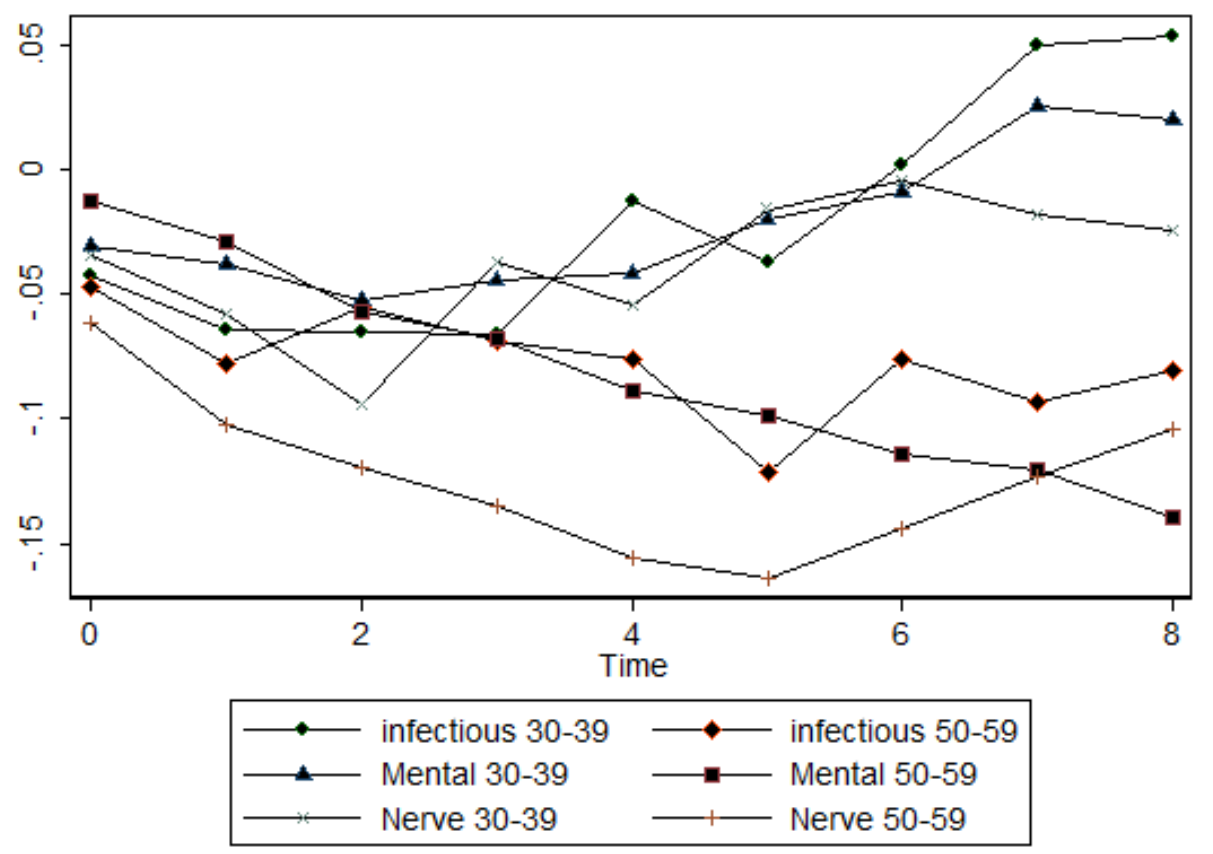


Table 1: Sample statistics for health shocks

\begin{tabular}{lcccccc}
\hline & \multicolumn{2}{c}{ Age $30-39$} & \multicolumn{2}{c}{ Age $40-49$} & \multicolumn{2}{c}{ Age 50-59 } \\
& $\begin{array}{l}\text { Low } \\
\text { edu. }\end{array}$ & $\begin{array}{c}\text { High } \\
\text { edu. }\end{array}$ & $\begin{array}{c}\text { Low } \\
\text { edu. }\end{array}$ & $\begin{array}{c}\text { High } \\
\text { edu. }\end{array}$ & $\begin{array}{c}\text { Low } \\
\text { edu. }\end{array}$ & $\begin{array}{c}\text { High } \\
\text { edu. }\end{array}$ \\
\hline Any Shock (\%) & 3.90 & 2.46 & 4.50 & 2.94 & 5.69 & 4.12 \\
Infectious diseases (\%) & 0.19 & 0.17 & 0.16 & 0.14 & 0.19 & 0.16 \\
Cancer (\%) & 0.08 & 0.08 & 0.18 & 0.18 & 0.30 & 0.29 \\
Mental \& behavioral (\%) & 0.79 & 0.27 & 0.91 & 0.36 & 0.73 & 0.39 \\
Nerve system (\%) & 0.12 & 0.06 & 0.13 & 0.08 & 0.15 & 0.10 \\
Heart diseases (\%) & 0.17 & 0.12 & 0.48 & 0.30 & 1.18 & 0.77 \\
Respiratory diseases (\%) & 0.25 & 0.16 & 0.24 & 0.17 & 0.37 & 0.23 \\
Digestive organs (\%) & 0.46 & 0.34 & 0.57 & 0.38 & 0.73 & 0.53 \\
Musculoskeletal (\%) & 0.22 & 0.13 & 0.27 & 0.18 & 0.33 & 0.22 \\
Genitourinary (\%) & 0.29 & 0.19 & 0.30 & 0.23 & 0.30 & 0.25 \\
External accidents (\%) & 0.74 & 0.39 & 0.75 & 0.47 & 0.79 & 0.60 \\
\hline
\end{tabular}

Notes: The table reports the fraction affected by any health shocks and the ten most common types of health shocks in 1995 (excluding the group symptoms, signs and abnormal clinical and laboratory findings, not elsewhere classified). High education is defined as having some kind of university education and low education less than university education. 
Table 2: Sample statistics for background characteristics and earnings

\begin{tabular}{|c|c|c|c|c|c|c|}
\hline & \multicolumn{2}{|c|}{ Age $30-39$} & \multicolumn{2}{|c|}{ Age $40-49$} & \multicolumn{2}{|c|}{ Age $50-59$} \\
\hline & Control & Shock & Control & Shock & Control & Shock \\
\hline \multicolumn{7}{|l|}{ Background characteristics: } \\
\hline Age & 34.3 & 34.6 & 44.6 & 44.9 & 54.0 & 54.3 \\
\hline Male & 0.54 & 0.59 & 0.50 & 0.53 & 0.50 & 0.54 \\
\hline Married & 0.45 & 0.43 & 0.65 & 0.60 & 0.70 & 0.67 \\
\hline Immigrant & 0.096 & 0.11 & 0.10 & 0.12 & 0.093 & 0.10 \\
\hline Child in household & 0.63 & 0.59 & 0.62 & 0.55 & 0.18 & 0.16 \\
\hline Children $0-3$ & 0.32 & 0.27 & 0.066 & 0.057 & 0.0050 & 0.0055 \\
\hline Children $4-6$ & 0.29 & 0.27 & 0.12 & 0.098 & 0.0093 & 0.0090 \\
\hline Children 7 - 10 & 0.27 & 0.27 & 0.23 & 0.20 & 0.030 & 0.027 \\
\hline Children $11-15$ & 0.15 & 0.17 & 0.37 & 0.33 & 0.097 & 0.086 \\
\hline Children $16-17$ & 0.027 & 0.036 & 0.19 & 0.18 & 0.079 & 0.069 \\
\hline Primary and lower sec. edu. & 0.010 & 0.016 & 0.086 & 0.11 & 0.24 & 0.27 \\
\hline Primary and lower sec. edu. & 0.13 & 0.17 & 0.13 & 0.15 & 0.078 & 0.076 \\
\hline Upper secondary edu. & 0.41 & 0.44 & 0.33 & 0.35 & 0.29 & 0.30 \\
\hline Upper secondary edu. & 0.12 & 0.10 & 0.12 & 0.11 & 0.12 & 0.12 \\
\hline Post-secondary edu. & 0.17 & 0.15 & 0.16 & 0.14 & 0.11 & 0.11 \\
\hline Post-secondary edu. & 0.13 & 0.100 & 0.16 & 0.13 & 0.14 & 0.12 \\
\hline Postgraduate education & 0.0061 & 0.0039 & 0.0095 & 0.0067 & 0.011 & 0.0089 \\
\hline \multicolumn{7}{|l|}{ Labor earnings: } \\
\hline Employed & 0.92 & 0.90 & 0.95 & 0.93 & 0.95 & 0.94 \\
\hline Mean & 166,273 & 156,713 & 193,406 & 177,882 & 200,434 & 186,006 \\
\hline P25 & 108,800 & 98,200 & 133,700 & 118,000 & 135,200 & 120100 \\
\hline Median & 164,300 & 155,700 & 180,500 & 170,100 & 185,200 & 176100 \\
\hline P75 & 213,800 & 205,300 & 231,900 & 220,900 & 240,000 & 230,000 \\
\hline
\end{tabular}

\begin{tabular}{lcc}
\hline \# observations & 378,392 & 434,354 \\
\hline $\begin{array}{l}\text { Note: The table reports background statistics for our analysis sample. The individual is considered } \\
\text { employed if he/she has a job in November each given year. An immigrant is an individual born }\end{array}$
\end{tabular}
outside of Sweden. Earnings is reported in SEK (10 SEK $\approx 1 €)$. 
Table 3: Estimates of the short-run and long-run effects of health shocks

\begin{tabular}{|c|c|c|c|c|}
\hline & (1) & $(2)$ & $(3)$ & (4) \\
\hline Shock year & $\begin{array}{c}-0.132^{* *} \\
(0.00121)\end{array}$ & $\begin{array}{l}-0.119^{* *} \\
(0.00113)\end{array}$ & $\begin{array}{c}-0.119^{* *} \\
(0.000861)\end{array}$ & $\begin{array}{c}-0.0898^{* *} \\
(0.000759)\end{array}$ \\
\hline Shock year +1 & $\begin{array}{l}-0.149^{* *} \\
(0.00135)\end{array}$ & $\begin{array}{l}-0.135^{* *} \\
(0.00127)\end{array}$ & $\begin{array}{l}-0.138^{* *} \\
(0.00105)\end{array}$ & $\begin{array}{l}-0.100^{* *} \\
(0.00102)\end{array}$ \\
\hline Shock year +2 & $\begin{array}{l}-0.153^{* *} \\
(0.00144)\end{array}$ & $\begin{array}{c}-0.140^{* *} \\
(0.00134)\end{array}$ & $\begin{array}{l}-0.143^{* *} \\
(0.00117)\end{array}$ & $\begin{array}{c}-0.0974^{* *} \\
(0.00126)\end{array}$ \\
\hline Shock year +3 & $\begin{array}{l}-0.171^{* *} \\
(0.00150)\end{array}$ & $\begin{array}{l}-0.159^{* *} \\
(0.00141)\end{array}$ & $\begin{array}{l}-0.162^{* *} \\
(0.00125)\end{array}$ & $\begin{array}{l}-0.108^{* *} \\
(0.00151)\end{array}$ \\
\hline Shock year +4 & $\begin{array}{l}-0.192^{* *} \\
(0.00162)\end{array}$ & $\begin{array}{l}-0.182^{* *} \\
(0.00152)\end{array}$ & $\begin{array}{l}-0.185^{* *} \\
(0.00138)\end{array}$ & $\begin{array}{l}-0.123^{* *} \\
(0.00176)\end{array}$ \\
\hline Shock year +5 & $\begin{array}{l}-0.212^{* *} \\
(0.00178)\end{array}$ & $\begin{array}{c}-0.201^{* *} \\
(0.00168)\end{array}$ & $\begin{array}{l}-0.203^{* *} \\
(0.00153)\end{array}$ & $\begin{array}{l}-0.133^{* *} \\
(0.00212)\end{array}$ \\
\hline Shock year +6 & $\begin{array}{c}-0.233^{* *} \\
(0.00193)\end{array}$ & $\begin{array}{l}-0.222^{* *} \\
(0.00182)\end{array}$ & $\begin{array}{l}-0.221^{* *} \\
(0.00164)\end{array}$ & $\begin{array}{l}-0.145^{* *} \\
(0.00242)\end{array}$ \\
\hline Shock year +7 & $\begin{array}{c}-0.253^{* *} \\
(0.00209)\end{array}$ & $\begin{array}{l}-0.243^{* *} \\
(0.00196)\end{array}$ & $\begin{array}{l}-0.240^{* *} \\
(0.00176)\end{array}$ & $\begin{array}{l}-0.156^{* *} \\
(0.00273)\end{array}$ \\
\hline Shock year +8 & $\begin{array}{l}-0.271^{* *} \\
(0.00243)\end{array}$ & $\begin{array}{l}-0.261^{* *} \\
(0.00229)\end{array}$ & $\begin{array}{l}-0.256^{* *} \\
(0.00203)\end{array}$ & $\begin{array}{l}-0.164^{* *} \\
(0.00311)\end{array}$ \\
\hline Shock year +9 & $\begin{array}{c}-0.282^{* *} \\
(0.00266)\end{array}$ & $\begin{array}{l}-0.273^{* *} \\
(0.00250)\end{array}$ & $\begin{array}{l}-0.266^{* *} \\
(0.00219)\end{array}$ & $\begin{array}{l}-0.166^{* *} \\
(0.00340)\end{array}$ \\
\hline Shock year +10 & $\begin{array}{c}-0.292^{* *} \\
(0.00308)\end{array}$ & $\begin{array}{c}-0.285^{* *} \\
(0.00291)\end{array}$ & $\begin{array}{l}-0.275^{* *} \\
(0.00249)\end{array}$ & $\begin{array}{l}-0.168^{* *} \\
(0.00377)\end{array}$ \\
\hline Time variables & Yes & Yes & Yes & Yes \\
\hline Controls & No & Yes & No & No \\
\hline Individual fixed & No & No & Yes & Yes \\
\hline Calender time & No & No & Yes & Yes \\
\hline Time fixed & No & No & Yes & Yes \\
\hline Linear trends & No & No & No & Yes \\
\hline \# observations & $17,679,410$ & $16,688,491$ & $17,679,410$ & $17,679,410$ \\
\hline
\end{tabular}

Note: The outcome is yearly labor earnings divided by the mean earnings in the control group. Controls include gender, marital status, number of kids in different age groups, level of education, immigrant status, age, residence municipality, and sector of employment (2 digits). Standard errors robust to heteroscedasticity and serial correlation. ${ }^{*}$ and ${ }^{* *}$ indicate significance at 5 and 1 percent level, respectively. 
Table 4: Estimates of heterogeneous effects by level of education and age

\begin{tabular}{|c|c|c|c|c|c|c|}
\hline & \multicolumn{2}{|c|}{ Age $30-39$} & \multicolumn{2}{|c|}{ Age $40-49$} & \multicolumn{2}{|c|}{ Age $50-59$} \\
\hline & Main & $\begin{array}{l}\text { Low } \\
\text { edu. }\end{array}$ & Main & $\begin{array}{l}\text { Low } \\
\text { edu. }\end{array}$ & Main & $\begin{array}{l}\text { Low } \\
\text { edu. }\end{array}$ \\
\hline Shock year & $\begin{array}{c}- \\
0.0528^{* *} \\
(0.00270)\end{array}$ & $\begin{array}{c}- \\
0.0431^{* *} \\
(0.00283)\end{array}$ & $\begin{array}{c}- \\
0.0531^{* *} \\
(0.00198)\end{array}$ & $\begin{array}{c}- \\
0.0484^{* *} \\
(0.00203)\end{array}$ & $\begin{array}{c}- \\
0.0581^{* *} \\
(0.00194)\end{array}$ & $\begin{array}{c}- \\
0.0544^{* *} \\
(0.00191)\end{array}$ \\
\hline Shock year +2 & $\begin{array}{c}- \\
0.0740^{* *} \\
(0.00495)\end{array}$ & $\begin{array}{c}- \\
0.0415^{* *} \\
(0.00509)\end{array}$ & $\begin{array}{c}- \\
0.0395^{* *} \\
(0.00311)\end{array}$ & $\begin{array}{c}- \\
0.0674^{* *} \\
(0.00321)\end{array}$ & $\begin{array}{c}- \\
0.0355^{* *} \\
(0.00315)\end{array}$ & $\begin{array}{c}- \\
0.0876^{* *} \\
(0.00313)\end{array}$ \\
\hline Shock year +5 & $\begin{array}{l}-0.135^{* *} \\
(0.00976)\end{array}$ & $\begin{array}{c}-0.0220 \\
(0.00992)\end{array}$ & $\begin{array}{c}- \\
0.0525^{* *} \\
(0.00527)\end{array}$ & $\begin{array}{c}- \\
0.0900^{* *} \\
(0.00539)\end{array}$ & $\begin{array}{c}- \\
0.0216^{* *} \\
(0.00519)\end{array}$ & $\begin{array}{l}-0.125^{* *} \\
(0.00508)\end{array}$ \\
\hline $\begin{array}{l}\text { Time variables } \\
\text { Controls } \\
\text { Individual fixed } \\
\text { Calendar time } \\
\text { Time Fixed } \\
\text { Linear trends }\end{array}$ & $\begin{array}{l}\mathrm{Ye} \\
\mathrm{Ye} \\
\mathrm{Ye} \\
\mathrm{Ye} \\
\mathrm{Ye} \\
\mathrm{Ye}\end{array}$ & & $\begin{array}{l}\mathrm{Y} \\
\mathrm{Y} \\
\mathrm{Y} \\
\mathrm{Y} \\
\mathrm{Y} \\
\mathrm{Y}\end{array}$ & & & $\begin{array}{l}\text { es } \\
\text { es } \\
\text { es } \\
\text { es } \\
\text { es } \\
\text { es }\end{array}$ \\
\hline
\end{tabular}

Note: The outcome is yearly labor earnings divided by the mean earnings among the non-treated with high respectively low education. High education is defined as some kind of university education and low education less than university education. Standard errors robust to heteroscedasticity and serial correlation. ${ }^{*}$ and ${ }^{* *}$ indicate significance at 5 and 1 percent level, respectively. 
Table 5: Estimates of heterogeneous effects by type of health shock, level of education and age

\begin{tabular}{|c|c|c|c|c|c|c|}
\hline & \multicolumn{2}{|c|}{ Age $30-39$} & \multicolumn{2}{|c|}{ Age $40-49$} & \multicolumn{2}{|c|}{ Age $50-59$} \\
\hline & Main & Low edu. & Main & Low edu. & Main & Low edu. \\
\hline \multicolumn{7}{|l|}{ Shock year } \\
\hline Infectious & -0.0137 & $-0.0426^{*}$ & $-0.0299 * *$ & $-0.0361 * *$ & -0.0234 & $-0.0471^{* *}$ \\
\hline Cancer & $-0.121^{* *}$ & $-0.0472^{*}$ & $-0.111^{* *}$ & $-0.0539 * *$ & $-0.140^{* *}$ & $-0.0731^{* *}$ \\
\hline Mental & $-0.158^{* *}$ & $-0.0311^{*}$ & $-0.152^{* *}$ & -0.00802 & $-0.142^{* *}$ & -0.0128 \\
\hline Nerve system & $-0.0728 * *$ & -0.0343 & $-0.0936^{* *}$ & -0.0180 & $-0.0626^{* *}$ & $-0.0620^{* *}$ \\
\hline Heart diseases & $-0.0382^{*}$ & $-0.0569 * *$ & $-0.0807 * *$ & $-0.0623^{* *}$ & $-0.0984^{* *}$ & $-0.0664^{* *}$ \\
\hline Respiratory & -0.0198 & -0.0197 & $-0.0379 * *$ & -0.0155 & $-0.0376^{* *}$ & $-0.0404^{* *}$ \\
\hline Digestive organs & $-0.0220^{* *}$ & $-0.0282^{* *}$ & $-0.0219 * *$ & $-0.0379 * *$ & $-0.0214^{* *}$ & $-0.0388^{* *}$ \\
\hline Musculoskeletal & $-0.0623^{* *}$ & $-0.0940 * *$ & $-0.0861^{* *}$ & $-0.0792^{* *}$ & $-0.0909^{* *}$ & $-0.0778^{* *}$ \\
\hline Genitourinary & -0.00868 & $-0.0317^{* *}$ & -0.0104 & $-0.0347 * *$ & -0.00863 & $-0.0336^{* *}$ \\
\hline External & $-0.0529 * *$ & $-0.0686^{* *}$ & $-0.0632^{* *}$ & $-0.0702^{* *}$ & $-0.0673^{* *}$ & $-0.0708^{* *}$ \\
\hline \multicolumn{7}{|l|}{ Shock year +2} \\
\hline Infectious & -0.0246 & $-0.0654^{*}$ & -0.0272 & -0.0378 & -0.0192 & $-0.0552^{*}$ \\
\hline Cancer & $-0.129 * *$ & -0.0173 & $-0.0386^{* *}$ & $-0.0572 * *$ & $-0.0435^{* *}$ & $-0.107^{* *}$ \\
\hline Mental & $-0.209 * *$ & $-0.0524^{*}$ & $-0.147^{* *}$ & $-0.0654^{* *}$ & $-0.125^{* *}$ & $-0.0574^{* *}$ \\
\hline Nerve system & -0.0602 & -0.0940 & $-0.113^{* *}$ & -0.0443 & $-0.0510^{*}$ & $-0.120^{* *}$ \\
\hline Heart diseases & $-0.0504^{*}$ & -0.0486 & $-0.0770 * *$ & $-0.0748 * *$ & $-0.116^{* *}$ & $-0.0950^{* *}$ \\
\hline Respiratory & -0.00605 & -0.0524 & -0.0373 & -0.0321 & -0.0222 & $-0.0841^{* *}$ \\
\hline Digestive organs & $-0.0492^{* *}$ & -0.0170 & -0.00141 & $-0.0612^{* *}$ & 0.0112 & $-0.0739^{* *}$ \\
\hline Musculoskeletal & -0.0275 & $-0.0995^{* *}$ & $-0.0417 * *$ & $-0.0836^{* *}$ & -0.0281 & $-0.109^{* *}$ \\
\hline Genitourinary & $-0.106^{* *}$ & -0.00413 & 0.00448 & $-0.0557 * *$ & 0.0248 & $-0.0718^{* *}$ \\
\hline External & $-0.0603^{* *}$ & $-0.0462^{* *}$ & $-0.0338^{* *}$ & $-0.0679 * *$ & -0.0146 & $-0.0864^{* *}$ \\
\hline \multicolumn{7}{|l|}{ Shock year +5} \\
\hline Infectious & -0.0913 & -0.0374 & -0.0350 & $-0.0696^{*}$ & -0.0181 & $-0.122^{* *}$ \\
\hline Cancer & $-0.123^{*}$ & -0.0185 & 0.00386 & $-0.0821 * *$ & $-0.0484^{*}$ & $-0.143^{* *}$ \\
\hline Mental & $-0.296^{* *}$ & -0.0204 & $-0.171^{* *}$ & $-0.0650 * *$ & -0.0388 & $-0.0985^{* *}$ \\
\hline Nerve system & $-0.199 * *$ & -0.0160 & $-0.151^{* *}$ & -0.0689 & -0.0331 & $-0.164^{* *}$ \\
\hline Heart diseases & $-0.100^{* *}$ & -0.0448 & $-0.110^{* *}$ & $-0.0809 * *$ & $-0.149^{* *}$ & $-0.111^{* *}$ \\
\hline Respiratory & -0.0679 & -0.0110 & -0.0402 & -0.0724 & 0.00855 & $-0.130^{* *}$ \\
\hline Digestive organs & $-0.0938^{*}$ & -0.0110 & -0.0139 & $-0.0848^{* *}$ & 0.0229 & $-0.112^{* *}$ \\
\hline Musculoskeletal & $-0.111^{* *}$ & -0.0394 & $-0.0458^{*}$ & $-0.110^{* *}$ & -0.0280 & $-0.119^{* *}$ \\
\hline Genitourinary & $-0.150^{* *}$ & -0.0150 & 0.0194 & $-0.104^{* *}$ & $0.0743^{* *}$ & $-0.128^{* *}$ \\
\hline External & $-0.116^{* *}$ & -0.0280 & $-0.0441^{* *}$ & $-0.0789 * *$ & 0.00497 & $-0.118^{* *}$ \\
\hline
\end{tabular}

Note: The outcome is yearly labor earnings divided by the mean earnings in the non-treated with high respectively low education. We report estimates for the ten most common types of health shocks. High education is defined as some kind of university education and low education less than university education. The models include controls for individual fixed effects, calender time fixed effect, and time with respect to the shock year fixed effects. Standard errors robust to heteroscedasticity and serial correlation. ${ }^{*}$ and ${ }^{* *}$ indicate significance at 5 and 1 percent level, respectively. 
Table 6: Placebo estimates by level of education and age

\begin{tabular}{|c|c|c|c|c|c|c|}
\hline & \multicolumn{2}{|c|}{ Age $30-39$} & \multicolumn{2}{|c|}{ Age $40-49$} & \multicolumn{2}{|c|}{ Age $50-59$} \\
\hline & Main & Low edu. & Main & Low edu. & Main & Low edu. \\
\hline Shock year-2 & $\begin{array}{l}-0.0128^{* *} \\
(0.00332)\end{array}$ & $\begin{array}{l}0.00597 \\
(0.00346)\end{array}$ & $\begin{array}{c}-0.00880^{* *} \\
(0.00218)\end{array}$ & $\begin{array}{l}0.00998^{* *} \\
(0.00223)\end{array}$ & $\begin{array}{c}-0.00756^{* *} \\
(0.00195)\end{array}$ & $\begin{array}{l}0.00624^{*} \\
(0.00193)\end{array}$ \\
\hline Shock year & $\begin{array}{c}-0.0598^{* *} \\
(0.00567)\end{array}$ & $\begin{array}{c}-0.0539^{* *} \\
(0.00593)\end{array}$ & $\begin{array}{c}-0.0622^{* *} \\
(0.00363)\end{array}$ & $\begin{array}{l}-0.0521^{* *} \\
(0.00373)\end{array}$ & $\begin{array}{c}-0.0644^{* *} \\
(0.00329)\end{array}$ & $\begin{array}{c}-0.0601^{* *} \\
(0.00328)\end{array}$ \\
\hline Shock year +2 & $\begin{array}{c}-0.0830^{* *} \\
(0.00858)\end{array}$ & $\begin{array}{c}-0.0563^{* *} \\
(0.00888)\end{array}$ & $\begin{array}{c}-0.0515^{* *} \\
(0.00521)\end{array}$ & $\begin{array}{c}-0.0727^{* *} \\
(0.00536)\end{array}$ & $\begin{array}{c}-0.0438^{* *} \\
(0.00470)\end{array}$ & $\begin{array}{c}-0.0955^{* *} \\
(0.00467)\end{array}$ \\
\hline Shock year +5 & $\begin{array}{c}-0.147^{* *} \\
(0.0144)\end{array}$ & $\begin{array}{c}-0.0426^{*} \\
(0.0147)\end{array}$ & $\begin{array}{c}-0.0689^{* *} \\
(0.00800)\end{array}$ & $\begin{array}{c}-0.0976^{* *} \\
(0.00818)\end{array}$ & $\begin{array}{c}-0.0329^{* *} \\
(0.00708)\end{array}$ & $\begin{array}{l}-0.136^{* *} \\
(0.00695)\end{array}$ \\
\hline Time variables & & & & & & \\
\hline Controls & & & & & & \\
\hline Individual fixed & & & & & & \\
\hline Calendar time & & & & & & \\
\hline Time Fixed & & es & & & & \\
\hline Linear trends & & & & & & \\
\hline
\end{tabular}


Table 7: Estimates of placebo effects by type of health shock, level of education and age

\begin{tabular}{|c|c|c|c|c|c|c|}
\hline & \multicolumn{2}{|c|}{ Age $30-39$} & \multicolumn{2}{|c|}{ Age $40-49$} & \multicolumn{2}{|c|}{ Age $50-59$} \\
\hline & Main & Low edu. & Main & Low edu. & Main & Low edu. \\
\hline \multicolumn{7}{|l|}{ Shock year-2 } \\
\hline Infectious & 0.00777 & -0.0159 & 0.00258 & -0.00225 & -0.00625 & -0.00346 \\
\hline Cancer & -0.0142 & -0.00635 & -0.00949 & 0.00417 & -0.0136 & 0.00754 \\
\hline Mental & -0.00867 & -0.00297 & -0.0138 & 0.00800 & -0.0151 & 0.0101 \\
\hline Nerve system & -0.0260 & 0.00722 & -0.0102 & 0.0162 & -0.00564 & -0.00132 \\
\hline Heart diseases & -0.0186 & 0.0155 & -0.0113 & 0.00989 & -0.0105 & 0.0112 \\
\hline Respiratory & -0.0278 & 0.0227 & -0.00225 & 0.00884 & -0.0112 & 0.0117 \\
\hline Digestive organs & -0.00966 & -0.000881 & -0.00836 & 0.00700 & -0.00297 & 0.00347 \\
\hline Musculoskeletal & -0.0116 & 0.00133 & -0.0174 & 0.0112 & -0.00168 & -0.00128 \\
\hline Genitourinary & -0.00584 & -0.00514 & 0.00237 & -0.00699 & -0.00651 & 0.00473 \\
\hline External & $-0.0233^{* *}$ & 0.0181 & -0.0115 & $0.0161^{*}$ & -0.00614 & 0.00410 \\
\hline \multicolumn{7}{|l|}{ Shock year } \\
\hline Infectious & 0.00322 & -0.0775 & -0.0258 & -0.0484 & -0.0234 & $-0.0702^{* *}$ \\
\hline Cancer & $-0.140^{* *}$ & -0.0626 & $-0.123^{* *}$ & $-0.0627^{* *}$ & $-0.157^{* *}$ & $-0.0840^{* *}$ \\
\hline Mental & $-0.180^{* *}$ & $-0.0709^{*}$ & $-0.189^{* *}$ & -0.0148 & $-0.166^{* *}$ & -0.0222 \\
\hline Nerve system & $-0.0910^{*}$ & -0.0462 & $-0.108^{* *}$ & -0.0102 & $-0.0693^{* *}$ & $-0.0818^{* *}$ \\
\hline Heart diseases & -0.0454 & -0.0532 & $-0.0938^{* *}$ & $-0.0608^{* *}$ & $-0.106^{* *}$ & $-0.0662^{* *}$ \\
\hline Respiratory & -0.0453 & -0.00700 & -0.0408 & -0.0152 & $-0.0405^{*}$ & $-0.0484^{* *}$ \\
\hline Digestive organs & -0.0213 & $-0.0478^{*}$ & $-0.0273^{*}$ & $-0.0431^{* *}$ & $-0.0249^{*}$ & $-0.0430^{* *}$ \\
\hline Musculoskeletal & $-0.0617^{*}$ & $-0.119^{* *}$ & $-0.105^{* *}$ & $-0.0871^{* *}$ & $-0.0977^{* *}$ & $-0.0938^{* *}$ \\
\hline Genitourinary & -0.00454 & $-0.0509^{*}$ & -0.00159 & $-0.0547^{* *}$ & -0.00896 & $-0.0388^{*}$ \\
\hline External & $-0.0694^{* *}$ & $-0.0647^{* *}$ & $-0.0742^{* *}$ & $-0.0686^{* *}$ & $-0.0706^{* *}$ & $-0.0755^{* *}$ \\
\hline \multicolumn{7}{|l|}{ Shock year+2 } \\
\hline Infectious & -0.00187 & -0.112 & -0.0218 & -0.0543 & -0.0190 & $-0.0862^{* *}$ \\
\hline Cancer & $-0.155^{* *}$ & -0.0382 & $-0.0549^{*}$ & $-0.0694^{* *}$ & $-0.0667^{* *}$ & $-0.122^{* *}$ \\
\hline Mental & $0.240^{* *}$ & $-0.107^{* *}$ & $-0.196^{* *}$ & $-0.0752^{* *}$ & $-0.157^{* *}$ & $-0.0706^{* *}$ \\
\hline Nerve system & -0.0840 & -0.110 & $-0.132^{* *}$ & -0.0343 & -0.0599 & $-0.146^{* *}$ \\
\hline Heart diseases & -0.0597 & -0.0440 & $-0.0945^{* *}$ & $-0.0730^{* *}$ & $-0.127^{* *}$ & $-0.0950^{* *}$ \\
\hline Respiratory & -0.0399 & -0.0359 & -0.0413 & -0.0320 & -0.0258 & $-0.0953^{* *}$ \\
\hline Digestive organs & $-0.0479^{*}$ & -0.0434 & -0.00850 & $-0.0685^{* *}$ & 0.00668 & $-0.0796^{* *}$ \\
\hline Musculoskeletal & -0.0263 & $-0.134^{* *}$ & $-0.0666^{* *}$ & $-0.0946^{* *}$ & -0.0372 & $-0.131^{* *}$ \\
\hline Genitourinary & $-0.100^{* *}$ & -0.0302 & 0.0164 & $-0.0827^{* *}$ & 0.0245 & $-0.0788^{* *}$ \\
\hline External & $-0.0820^{* *}$ & -0.0416 & $-0.0484^{* *}$ & $-0.0662^{* *}$ & -0.0188 & $-0.0928^{* *}$ \\
\hline \multicolumn{7}{|l|}{ Shock year +5} \\
\hline Infectious & -0.0601 & -0.102 & -0.0275 & -0.0925 & 0.0185 & $-0.164^{* *}$ \\
\hline Cancer & -0.159 & -0.0476 & -0.0185 & $-0.0994^{* *}$ & 0.0167 & $-0.164^{* *}$ \\
\hline Mental & $-0.338^{* *}$ & -0.0963 & $-0.239^{* *}$ & $-0.0792^{*}$ & $-0.0830^{* *}$ & $-0.117^{* *}$ \\
\hline Nerve system & $-0.231^{* *}$ & -0.0392 & $-0.177^{* *}$ & -0.0557 & -0.0450 & $-0.200^{* *}$ \\
\hline Heart diseases & -0.112 & -0.0389 & $-0.134^{* *}$ & $-0.0787^{*}$ & $-0.163^{* *}$ & $-0.111^{* *}$ \\
\hline Respiratory & -0.114 & 0.0112 & -0.0456 & -0.0725 & 0.00391 & $-0.146^{* *}$ \\
\hline Digestive organs & -0.0918 & -0.0475 & -0.0234 & $-0.0951^{* *}$ & 0.0168 & $-0.120^{* *}$ \\
\hline Musculoskeletal & $-0.109^{*}$ & -0.0873 & $-0.0799^{*}$ & $-0.126^{* *}$ & -0.0405 & $-0.150^{* *}$ \\
\hline Genitourinary & $-0.142^{* *}$ & -0.0512 & 0.0359 & $-0.141^{* *}$ & $0.0741^{*}$ & $-0.138^{* *}$ \\
\hline External & $-0.145^{* *}$ & -0.0221 & $-0.0640^{*}$ & $-0.0771^{* *}$ & -0.000669 & $-0.127^{* *}$ \\
\hline
\end{tabular}

Note: The outcome is yearly labor earnings divided by the mean earnings in the non-treated with high respectively low education. We report estimates for the ten most common types of health shocks. High education is defined as some kind of university education and low education less than university education. The models include controls for individual fixed effects, calender time fixed effect, and time with respect to the shock year fixed effects. Standard errors robust to heteroscedasticity and serial correlation. ${ }^{*}$ and ${ }^{* *}$ indicate significance at 5 and 1 percent level, respectively. 
Table 8: DID-matching estimates of the short-run and long-run effects of health shocks

\begin{tabular}{lllllll}
\hline & \multicolumn{2}{c}{ Age 30 -39 } & \multicolumn{2}{c}{ Age $40-49$} & \multicolumn{2}{c}{ Age 50 - 59 } \\
& Main & Low edu. & Main & Low edu. & Main & Low edu. \\
\multirow{2}{*}{ Shock year } & & & & & & \\
& $(0.00429)$ & $(0.00433)$ & $(0.00320)$ & $(0.00329)$ & $(0.00332)$ & $(0.00339)$ \\
\multirow{3}{*}{ Shock year+2 } & $0.0189^{* *}$ & $-0.141^{* *}$ & $-0.0357^{* *}$ & $-0.0806^{* *}$ & $-0.0612^{* *}$ & $-0.0634^{* *}$ \\
& $(0.00584)$ & $(0.00590)$ & $(0.00366)$ & $(0.00377)$ & $(0.00382)$ & $(0.00393)$ \\
\multirow{3}{*}{ Shock year+5 } & $0.0562^{* *}$ & $-0.217^{* *}$ & $-0.0314^{* *}$ & $-0.132^{* *}$ & $-0.0503^{* *}$ & $-0.111^{* *}$ \\
& $(0.00838)$ & $(0.00846)$ & $(0.00448)$ & $(0.00459)$ & $(0.00463)$ & $(0.00468)$
\end{tabular}

Note: The outcome is the difference in yearly labor earnings between 2 years before the shock and the current year divided by the mean earnings among the controls. Standard errors robust to heteroscedasticity and serial correlation. ${ }^{*}$ and ${ }^{* *}$ indicate significance at 5 and 1 percent level, respectively.

Table 9: Estimates of heterogeneous effects using a detailed measure of level of education

\begin{tabular}{lccccc}
\hline & Main & Level 2 & Level 3 & Level 4 & Level 5 \\
\hline Age 30 -39 & & & & & \\
Shock year & $-0.120^{* *}$ & $0.0177^{* *}$ & $0.0921^{* *}$ & $0.0204^{* *}$ & $0.130^{* *}$ \\
Shock year+2 & $-0.151^{* *}$ & $0.0314^{* *}$ & $0.117^{* *}$ & $0.0178^{*}$ & $0.157^{* *}$ \\
Shock year+5 & $-0.209^{* *}$ & $0.0505^{* *}$ & $0.160^{* *}$ & -0.00412 & $0.180^{* *}$ \\
\hline Age 40 - 49 & & & & & \\
Shock year & $-0.116^{* *}$ & $0.0137^{* *}$ & $0.0445^{* *}$ & $0.0415^{* *}$ & $0.0798^{* *}$ \\
Shock year+2 & $-0.131^{* *}$ & $0.0254^{* *}$ & $0.0701^{* *}$ & $0.0655^{* *}$ & $0.112^{* *}$ \\
Shock year+5 & $-0.178^{* *}$ & $0.0408^{* *}$ & $0.0998^{* *}$ & $0.0894^{* *}$ & $0.154^{* *}$ \\
\hline Age 50 - 59 & & & & & \\
Shock year & $-0.127^{* *}$ & $0.0121^{* *}$ & $0.0481^{* *}$ & $0.0543^{* *}$ & $0.0763^{* *}$ \\
Shock year+2 & $-0.146^{* *}$ & $0.0210^{* *}$ & $0.0758^{* *}$ & $0.0907^{* *}$ & $0.121^{* *}$ \\
Shock year+5 & $-0.179^{* *}$ & $0.0342^{* *}$ & $0.0990^{* *}$ & $0.123^{* *}$ & $0.175^{* *}$ \\
\hline
\end{tabular}

Note: The outcome yearly labor earnings divided by the mean earnings among the non-treated in each educational and age group. The excluded category is individuals with no high school education. Level 2 to 5 is short high school education ( 2 years or less), long high school education (3 years), short university education (2 years or less) and individuals with long university education (more than 2 years). The models include controls for individual fixed effects, calender time fixed effect, and time with respect to the shock year fixed effects. Standard errors robust to heteroscedasticity and serial correlation. ${ }^{*}$ and ${ }^{* *}$ indicate significance at 5 and 1 percent level, respectively. 
Table 10: Sample statistics on fraction of deaths

\begin{tabular}{lcccccc}
\hline & \multicolumn{2}{c}{ Age 30 } & Low edu. & High & Low edu. & High \\
& & edu. & & edu. & Low edu. & $\begin{array}{c}\text { High } \\
\text { edu. }\end{array}$ \\
\hline Control (\%) & 0.49 & 0.29 & 1.08 & 0.62 & 3.09 & 1.90 \\
Shock (\%) & 3.25 & 2.26 & 7.51 & 5.49 & 13.55 & 9.98 \\
Total (\%) & 1.74 & 1.04 & 4.48 & 2.88 & 9.42 & 6.43 \\
\hline Observations & 264,007 & 107,643 & 300,638 & 128,937 & 317,419 & 104,937 \\
\hline
\end{tabular}

Note: The table reports the fraction in our analysis sample that dies within the observation period.

Table 11: Estimates of heterogeneous effects using only those that survives throughout the entire observation period

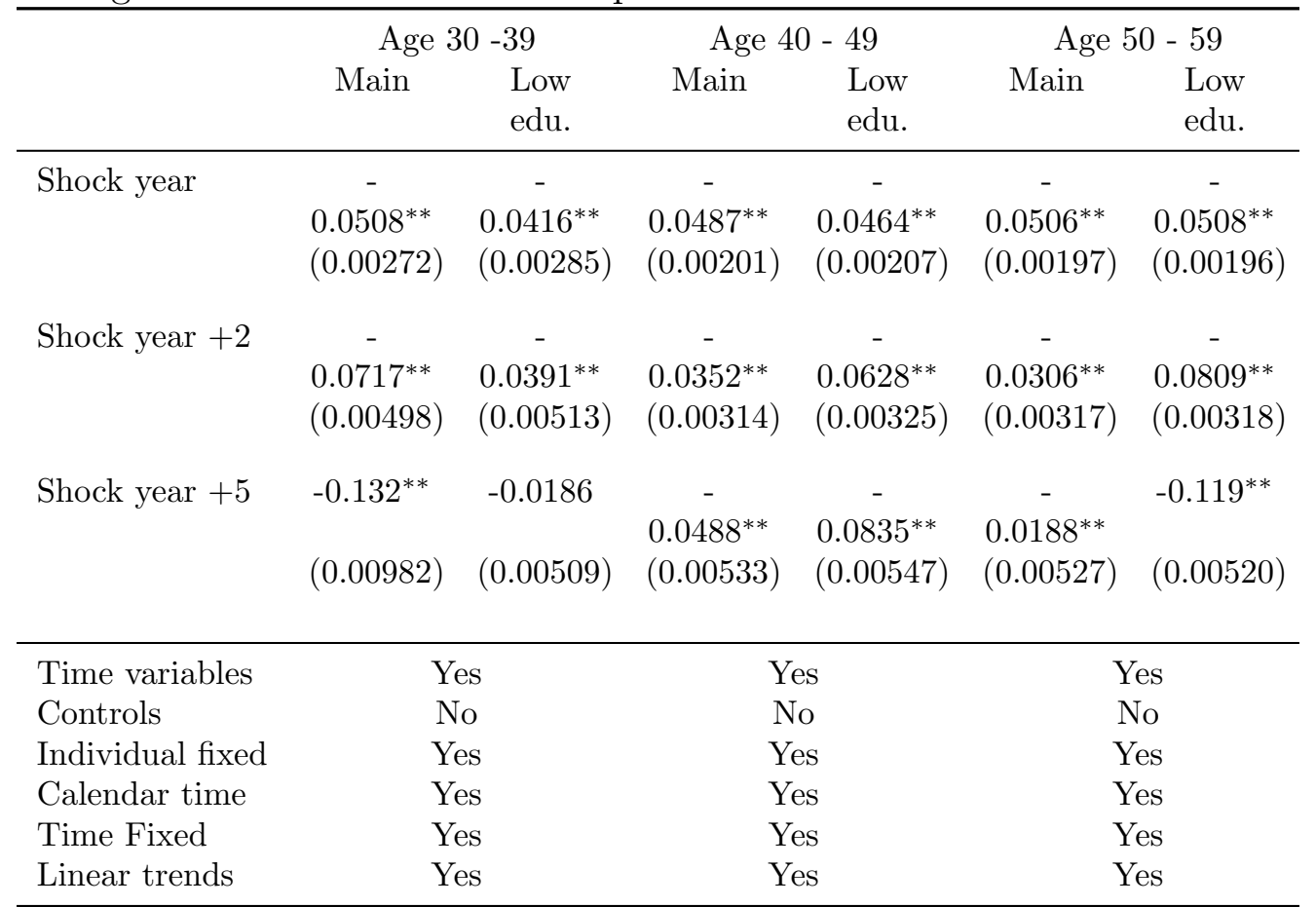

Note: The outcome is yearly labor earnings divided by the mean earnings among the non-treated with high respectively low education. High education is defined as some kind of university education and low education less than university education. Standard errors robust to heteroscedasticity and serial correlation. ${ }^{*}$ and ${ }^{* *}$ indicate significance at 5 and 1 percent level, respectively. 
Table 12: Sample statistics on number of diagnoses and medical procedures Age 30-39 Age 40-49 Age 50-59

Low edu. High edu. Low edu. High edu. Low edu. High edu.

\begin{tabular}{lcccccc}
\hline \# of diagnoses & \multicolumn{7}{c}{} & & \\
1 & 77.76 & 78.58 & 74.47 & 75.67 & 69.99 & 71.50 \\
2 & 17.15 & 16.77 & 19.11 & 18.48 & 21.43 & 20.68 \\
3 & 3.719 & 3.445 & 4.675 & 4.238 & 6.181 & 5.595 \\
$\geq 4$ & 1.373 & 1.203 & 1.745 & 1.620 & 2.399 & 2.227 \\
\hline \# of medical procedures & & & & & \\
0 & 0.69 & 0.68 & 0.70 & 0.68 & 0.72 & 0.71 \\
1 & 0.22 & 0.24 & 0.21 & 0.22 & 0.18 & 0.19 \\
2 & 0.060 & 0.063 & 0.066 & 0.070 & 0.064 & 0.066 \\
$\geq 3$ & 0.025 & 0.024 & 0.028 & 0.030 & 0.032 & 0.036 \\
\hline Observations & 119,224 & 40,582 & 158,988 & 59,770 & 191,954 & 58,766 \\
\hline
\end{tabular}

Note: The table reports the fraction of the treated in the analysis sample with a certain number of diagnoses and medical procedures. Number of diagnoses reports includes the main diagnose. Number of medical procedures counts as registered medical procedures for the current hospitalization. 
Table 13: Estimates of heterogeneous effects controlling for number of diagnoses and medical procedures

\begin{tabular}{|c|c|c|c|}
\hline & $\begin{array}{l}\text { Shock year } \\
\text { Low edu. }\end{array}$ & $\begin{array}{l}\text { Shock year+2 } \\
\text { Low edu. }\end{array}$ & $\begin{array}{l}\text { Shock year }+5 \\
\text { Low edu. }\end{array}$ \\
\hline \multicolumn{4}{|l|}{ Age 30-39 } \\
\hline Baseline & $-0.0431^{* *}$ & $-0.0415^{* *}$ & -0.0220 \\
\hline \#diagnoses & $-0.0426^{* *}$ & $-0.0409^{* *}$ & $-0.0213^{* *}$ \\
\hline \#operations & $-0.0426^{* *}$ & $-0.0404^{* *}$ & -0.0206 \\
\hline \multicolumn{4}{|l|}{ Age $40-49$} \\
\hline Baseline & $-0.0484^{* *}$ & $-0.0674^{* *}$ & $-0.09000^{* *}$ \\
\hline \#diagnoses & $-0.0477^{* *}$ & $-0.138^{* *}$ & $-0.0886^{* *}$ \\
\hline \#operations & $-0.0483^{* *}$ & $-0.0661^{* *}$ & $-0.0881^{* *}$ \\
\hline \multicolumn{4}{|l|}{ Age 50-59 } \\
\hline Baseline & $-0.0544^{* *}$ & $-0.0876^{* *}$ & $-0.125^{* *}$ \\
\hline \#diagnoses & $-0.0533^{* *}$ & $-0.0861^{* *}$ & $-0.124^{* *}$ \\
\hline \#operations & -0.0546 & $-0.0871^{* *}$ & $-0.125^{* *}$ \\
\hline Time variables & Yes & Yes & Yes \\
\hline Controls & Yes & Yes & Yes \\
\hline Individual f.e & Yes & Yes & Yes \\
\hline Calendar time & Yes & Yes & Yes \\
\hline Time f.e & Yes & Yes & Yes \\
\hline Linear trends & Yes & Yes & Yes \\
\hline \multicolumn{4}{|c|}{$\begin{array}{l}\text { Note: The outcome is yearly labor earnings divided by the mean earnings among the non-treated with } \\
\text { high respectively low education. Each row reports results from one specification. The specification } \\
\text { with number of diagnoses includes an interaction effect between our treatment effect and number of } \\
\text { diagnoses number of diagnoses }(1,2,3, \text { or } \geq 4) \text {, and the number of operations specification includes } \\
\text { and an interaction between the treatment effect and number of medical procedures }(0,1,2 \text {, or } \geq 3) \text {. } \\
\text { High education is defined as some kind of university education and low education less than university } \\
\text { education. Standard errors are robust to heteroscedasticity and serial correlation. }{ }^{*} \text { and }{ }^{* *} \text { indicate } \\
\text { significance at } 5 \text { and } 1 \text { percent level, respectively. }\end{array}$} \\
\hline
\end{tabular}


Table 14: Estimates of heterogeneous effects controlling for length of stay, type of hospital and occupation

$\begin{array}{ccc}\text { Shock year } & \text { Shock year }+2 & \text { Shock year }+5 \\ \text { Low edu. } & \text { Low edu. } & \text { Low edu. }\end{array}$

\begin{tabular}{|c|c|c|c|}
\hline \multicolumn{4}{|l|}{ Age $30-39$} \\
\hline Baseline & $-0.0431^{* *}$ & $-0.0415^{* *}$ & -0.0220 \\
\hline length of stay & $-0.0417^{* *}$ & $-0.0402^{* *}$ & -0.0202 \\
\hline university hosp. & $-0.0433^{* *}$ & $-0.0414^{* *}$ & -0.0214 \\
\hline occupation & $-0.0426^{* *}$ & $-0.0465^{* *}$ & $-0.0356^{* *}$ \\
\hline \multicolumn{4}{|l|}{ Age $40-49$} \\
\hline Baseline & $-0.0484^{* *}$ & $-0.0674^{* *}$ & $-0.09000^{* *}$ \\
\hline length of stay & $-0.0172^{* *}$ & $-0.0658^{* *}$ & $-0.0880^{* *}$ \\
\hline university hosp. & $-0.0490^{* *}$ & $-0.0677^{* *}$ & $-0.0900^{* *}$ \\
\hline occupation & $-0.0578^{* *}$ & $-0.0813^{* *}$ & $-0.112^{* *}$ \\
\hline \multicolumn{4}{|l|}{ Age 50-59 } \\
\hline Baseline & $-0.0544^{* *}$ & $-0.0876^{* *}$ & $-0.125^{* *}$ \\
\hline length of stay & $-0.0506^{* *}$ & $-0.0840^{* *}$ & $-0.122^{* *}$ \\
\hline university hosp. & $-0.0553^{* *}$ & $-0.0881^{* *}$ & $-0.125^{* *}$ \\
\hline occupation & $-0.0616^{* *}$ & $-0.0892^{* *}$ & $-0.115^{* *}$ \\
\hline Time variables & Yes & Yes & Yes \\
\hline Controls & Yes & Yes & Yes \\
\hline Individual f.e & Yes & Yes & Yes \\
\hline Calendar time & Yes & Yes & Yes \\
\hline Time f.e & Yes & Yes & Yes \\
\hline Linear trends & Yes & Yes & Yes \\
\hline
\end{tabular}


Table 15: Estimates of heterogeneous effects on social insurance usage

\begin{tabular}{lcccccc}
\hline & \multicolumn{2}{c}{ Age $30-39$} & \multicolumn{2}{c}{ Age $40-49$} & \multicolumn{2}{c}{ Age 50 - 59 } \\
& Main & Low edu. & Main & Low edu. & Main & Low edu. \\
\cline { 1 - 3 } SI & & & & & & \\
Shock year & $0.274^{* *}$ & $0.0633^{* *}$ & $0.327^{* *}$ & $0.0231^{* *}$ & $0.340^{* *}$ & $0.0307^{* *}$ \\
& $(0.00293)$ & $(0.00324)$ & $(0.00251)$ & $(0.00276)$ & $(0.00257)$ & $(0.00272)$ \\
Shock year+2 & 0.00640 & $0.0769^{* *}$ & $0.0361^{* *}$ & $0.0270^{* *}$ & $0.0468^{* *}$ & $0.0229^{* *}$ \\
& $(0.00323)$ & $(0.00355)$ & $(0.00285)$ & $(0.00309)$ & $(0.00301)$ & $(0.00311)$ \\
& & & & & & \\
Shock year+5 & $-0.0545^{* *}$ & $0.109^{* *}$ & $-0.0186^{* *}$ & $0.0157^{* *}$ & $-0.0371^{* *}$ & 0.00842 \\
& $(0.00454)$ & $(0.00494)$ & $(0.00399)$ & $(0.00429)$ & $(0.00410)$ & $(0.00418)$
\end{tabular}

$\begin{array}{lcccccc}\text { DI } & & & & & \\ \text { Shock year } & 0.00126^{* *} & 0.00266^{* *} & 0.00436^{* *} & 0.00343^{* *} & 0.00687^{* *} & 0.00768^{* *} \\ & (0.000370) & (0.000462) & (0.00049) & (0.000600) & (0.000774) & (0.000838) \\ \text { Shock year+2 } & 0.0120^{* *} & 0.0144^{* *} & 0.0258^{* *} & 0.0211^{* *} & 0.0465^{* *} & 0.0449^{* *} \\ & (0.000819) & (0.00102) & (0.00103) & (0.00125) & (0.00152) & (0.00169) \\ \text { Shock year+5 } & 0.0254^{* *} & 0.0337^{* *} & 0.0514^{* *} & 0.0467^{* *} & 0.0819^{* *} & 0.0711^{* *} \\ & (0.00131) & (0.00163) & (0.00163) & (0.00197) & (0.00238) & (0.00258)\end{array}$

\begin{tabular}{lcccccc}
\hline UI & & & & & \\
Shock year & $-0.0119^{* *}$ & $0.0183^{* *}$ & $-0.00508^{* *}$ & $0.00966^{* *}$ & $-0.00483^{* *}$ & $0.00582^{* *}$ \\
& $(0.00170)$ & $(0.00188)$ & $(0.00115)$ & $(0.00126)$ & $(0.000989)$ & $(0.00100)$ \\
Shock year+2 & $-0.00980^{* *}$ & $0.0176^{* *}$ & -0.00111 & $0.00610^{*}$ & $-0.00728^{* *}$ & 0.00191 \\
& $(0.00252)$ & $(0.00281)$ & $(0.00177)$ & $(0.00194)$ & $(0.00155)$ & $(0.00158)$ \\
Shock year+5 & 0.000328 & -0.000417 & $0.00921^{* *}$ & $-0.0130^{* *}$ & $-0.00718^{*}$ & $-0.00813^{* *}$ \\
& $(0.00359)$ & $(0.00402)$ & $(0.00250)$ & $(0.00275)$ & $(0.00220)$ & $(0.00223)$
\end{tabular}

\begin{tabular}{lccc}
\hline Time variables & Yes & Yes & Yes \\
Controls & No & No & No \\
Individual f.e & Yes & Yes & Yes \\
Calendar time & Yes & Yes & Yes \\
Time f.e & Yes & Yes & Yes \\
Linear trends & Yes & Yes & Yes \\
\hline
\end{tabular}

Note: The outcome is the take-up of sickness insurance, disability insurance and unemployment insurance, respectively. Standard errors robust to heteroscedasticity and serial correlation. ${ }^{*}$ and ${ }^{* *}$ indicate significance at 5 and 1 percent level, respectively. 


\section{A Appendix}

Figure 8: Ratio between mean labor earnings for high educated shock (control) and low educated shock (control). By type of health shock

\section{Shock effects}

\section{by shock type}
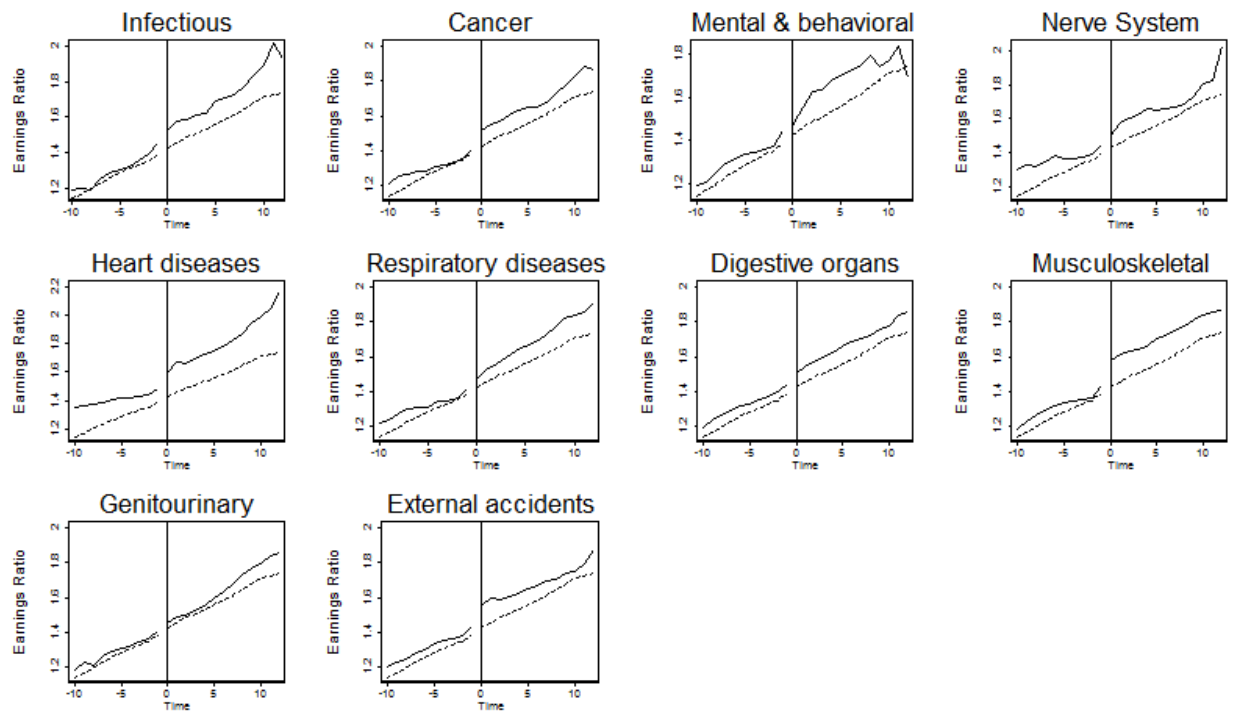

- Shod -- Control 